\title{
Dictamen de las Comisiones Unidas de Puntos Constitucionales; de Gobernación; de Reforma del Estado; de Estudios Legislativo Primera, y de Estudios Legislativos, Segunda, a la Minuta con Proyecto de Decreto por el que se reforman adicionan y derogan diversas disposiciones de la Constitución Política de los Estados Unidos Mexicanos en Materia Político-Electoral
}

HONORABLE ASAMBLEA:

A las Comisiones Unidas de Puntos Constitucionales; de Gobernación; de Reforma del Estado; de Estudios Legislativos, Primera, y de Estudios Legislativos Segunda, de la Cámara de Senadores de la LXII Legislatura del Honorable Congreso de la Unión, les fue turnada para su estudio y dictamen, la Minuta de Cámara de Diputados con Proyecto de Decreto por el que se reforman, adicionan y derogan diversas disposiciones de la Constitución Política de los Estados Unidos Mexicanos, en materia política-electoral.

Los integrantes de estas Comisiones Unidas procedimos al estudio de la Minuta, analizando en detalle las consideraciones y fundamentos que sirven de apoyo a la reforma que se propone, a fin de formular y emitir su dictamen conforme a las facultades que les confieren los artículos 85, párrafo 2, inciso a); 86, 89 y 94 de la Ley Orgánica del Congreso General de los Estados Unidos Mexicanos; así como los artículos 113, 117, 135, 178, 182, 188, 190, 220 y 221 del Reglamento del Senado de la República, al tenor de la siguiente:

\section{METODOLOGÍA}

1. En el capítulo de “ANTECEDENTES”, se da constancia del proceso legislativo y de la recepción y turno para la elaboración del dictamen de la referida Minuta. 
II. En el capítulo correspondiente a "CONTENIDO DEL PROYECTO DE DECRETO", se sintetiza la propuesta de la reforma en estudio.

III. En el capítulo de “CONSIDERACIONES”, se expresan las razones que sustentan la valoración de la propuesta de reforma constitucional.

IV. En el capítulo de "MODIFICACIONES A LA MINUTA", se expresan en un cuadro comparativo los cambios en la redacción que propone la Cámara de Diputados, en relación con lo aprobado por la Cámara de Senadores.

V. En la sección relativa al "TEXTO NORMATIVO Y RÉGIMEN TRANSITORIO", se plantea el Decreto por el que se reforman, adicionan y derogan diversas disposiciones de la Constitución Política de los Estados Unidos Mexicanos, en materia política-electoral.

Establecida la metodología para la elaboración del dictamen procedente, estas Comisiones Unidas procedemos a elaborar los siguientes:

\section{ANTECEDENTES}

1. Con fecha 2 de diciembre de 2013, el Pleno de la Cámara de Senadores dio primera lectura al Dictamen Proyecto de Decreto por el que se reforman, adicionan y derogan diversas disposiciones de la Constitución Política de los Estados Unidos Mexicanos, en materia política-electoral.

2. El 3 de diciembre de 2013, el Pleno de la Cámara de Senadores, aprobó por 107 votos en pro, 16 en contra y 1 abstención, el Dictamen con Proyecto de Decreto por el que se reforman, adicionan y derogan diversas disposiciones de la Constitución Política de los Estados Unidos Mexicanos, en materia política-electoral, enviándola a la Cámara de Diputados para sus efectos constitucionales.

3. El 4 de diciembre de 2013, la Cámara de Senadores remitió a la Cámara de Diputados el expediente relativo al Proyecto de Decreto por el que se reforman y adicionan diversas disposiciones de la Constitución Política de los Estados Unidos Mexicanos, en materia política-electoral.

4. El 5 de diciembre de 2013, en sesión de la Cámara de Diputados, fue aprobado por 409 votos en pro, 69 en contra y 3 abstenciones, el dictamen de la Minuta con Proyecto de Decreto por el que se reforman, adicionan y derogan diversas disposiciones de la Constitución 
Política de los Estados Unidos Mexicanos, en materia política-electoral, y fue turnado a la Cámara de Senadores para los efectos del inciso E del artículo 72 constitucional.

5. El propio 5 de diciembre 2013, la Cámara de Diputados remitió al Senado de la República la Minuta con Proyecto de Decreto por el que se reforman y adicionan diversas disposiciones de la Constitución Política de los Estados Unidos Mexicanos, en materia político-electoral, para los efectos del párrafo E del artículo 72 constitucional.

6. El 6 de diciembre de 2013, el Presidente la Mesa Directiva del Senado, con fundamento en lo dispuesto por el artículo 176 del Reglamento del Senado, dispuso el turno directo de la minuta referida en el punto anterior a las Comisiones Unidas que suscriben, a fin de que procedieron al análisis de la misma y formular el dictamen procedente.

Establecidos los antecedentes, las Comisiones Unidas procedemos a señalar puntualmente el objeto y la descripción de la Minuta.

\section{CONTENIDO DEL PROYECTO DE DECRETO}

La Minuta proveniente de la Cámara de Diputados, contiene el proyecto de decreto por el que se reforman los párrafos segundo y cuarto del apartado A del artículo 26; la fracción VIl del párrafo vigésimo segundo del artículo 28; el primer párrafo del artículo 29; la fracción VIl y los numerales 40. y 6O. de la fracción VIII del artículo 35; la base 1 en sus párrafos inicial y segundo, el tercer párrafo de la base 11, la base 111 en su párrafo inicial, el apartado A en su párrafo inicial e incisos a), e), e) y g) y en su segundo párrafo, el apartado B en su primer párrafo e inciso e) y su segundo párrafo, el apartado $\mathrm{C}$ en su primer párrafo y el apartado $\mathrm{D}$, la base IV en su párrafo inicial y la base $\mathrm{V}$ del artículo 41; la fracción 11 del artículo 5 4; el segundo párrafo de la fracción V del artículo 55; el artículo 59; el primer párrafo del artículo 65; el segundo párrafo del artículo 69; el inciso a) de la fracción XXI del artículo 73; el tercer párrafo de la fracción IV del artículo 74; la fracción 11 del artículo 76; la fracción VI del artículo 82; el artículo 83; el segundo párrafo del artículo 84; la fracción IX del artículo 89, el segundo párrafo del artículo 93; la fracción VI del artículo 95; las fracciones VIl y VIII del artículo 99; el apartado A del artículo 1 02; los incisos e) y f) del segundo párrafo de la fracción 11 y la fracción 111 del artículo 105 ; el segundo párrafo de la fracción V, el segundo párrafo 
de la fracción VIII, los párrafos primero y tercero de la fracción XIII y la fracción XV del artículo 107, el primer párrafo del artículo $11 \mathrm{O}$, el primer párrafo del artículo 111; el encabeza do y el segundo párrafo de la fracción 1 del artículo 115; los párrafos segundo y tercero de la fracción 11, el primer párrafo y los incisos a), b), e), d), h), j), y k) de la fracción IV del artículo 116; el segundo párrafo del artículo 119, la fracción 111 de la BASE PRIMERA del apartado C del artículo 122; se adicionan un aparado $\mathrm{C}$ al artículo 26; un cuarto párrafo a la base 1 y un tercer, cuarto y quinto párrafos de la base VI del artículo 41, un tercer párrafo al artículo 69; la fracción XXIX-U al artículo 73; las fracciones III y VII al artículo 74; las fracciones XI y XII, recorriéndose la subsecuente en su orden, al artículo 76; un segundo y tercer párrafos a la fracción 11 y la fracción XVII al artículo 89; los párrafos tercero y cuarto al artículo 90; la fracción IX, recorriéndose la subsecuente en su orden, al artículo 99; un inciso h) al segundo párrafo de la fracción 11 del artículo 1 05; un segundo párrafo al inciso f) y un inciso $\mathrm{n}$ ), recorriéndose en el orden el subsecuente a la facción IV, así como una fracción VIII al artículo 116; y se deroga la fracción V del artículo 78, de la Constitución Política de los Estados Unidos Mexicanos.

Con motivo de la discusión y votación en la Cámara de Diputados de la minuta remitida por el Senado de la República, la Colegisladora estimó pertinente aprobar esos términos los textos previamente votados en sentido positivo por la Cámara de Senadores, con excepción de doce modificaciones, que se ilustran en el siguiente apartado del presente dictamen, sin demérito de referirnos específicamente a cada una de ellas.

Establecido el objeto y la descripción del contenido de la Minuta, las Comisiones Unidas realizan las siguientes:

\section{CONSIDERACIONES}

PRIMERA.- Las Comisiones dictaminadoras estimamos de utilidad la elaboración de un cuadro comparativo entre la Minuta enviada por el Senado de la República el día 04 de diciembre de 2012 y la Minuta recibida de la Cámara de Diputados aprobada por el Pleno de la misma el día 05 de diciembre de 2013, con objeto de identificar cuáles son los cambios realizados por la Cámara revisora. 
Esta revista forma parte del acervo de la Biblioteca Jurídica Virtual del Instituto de Investigaciones Jurídicas de la UNAM

\begin{tabular}{|c|c|}
\hline MINUTA CÁMARA DE SENADORES & MINUTA CÁMARA DE DIPUTADOS \\
\hline $\begin{array}{l}\text { Artículo } 26 . \\
\text { C... } \\
\text { (segundo párrafo) } \\
\text { El Consejo Nacional de Evaluación de la } \\
\text { Política de Desarrollo Social estará inte- } \\
\text { grado por un Presidente y seis Consejeros } \\
\text { que deberán ser ciudadanos mexicanos de } \\
\text { reconocido prestigio en los sectores privado } \\
\text { y social, así como en los ámbitos académico } \\
\text { y profesional; tener experiencia mínima de } \\
\text { diez años en materia de desarrollo social, } \\
\text { y no pertenecer a algún partido político o } \\
\text { haber sido candidato a ocupar un cargo pú- } \\
\text { blico de elección popular. Serán nombrados, } \\
\text { bajo el procedimiento que determine la ley, } \\
\text { por el voto de las dos terceras partes de los } \\
\text { miembros presentes de la Cámara de Sena- } \\
\text { dores. El nombramiento podrá ser objeta- } \\
\text { do por el Presidente de la República en un } \\
\text { plazo de diez días hábiles y, si no lo hiciere, } \\
\text { ocupará el cargo de consejero la persona } \\
\text { nombrada por el Senado de la República. } \\
\text { Cada cuatro años serán sustituidos los dos } \\
\text { consejeros de mayor antigüedad en el cargo, } \\
\text { salvo que fuesen pospuestos y ratificados } \\
\text { para un segundo periodo. }\end{array}$ & $\begin{array}{l}\text { Artículo } 26 . \\
\text { C... } \\
\text { El Consejo Nacional de Evaluación de la } \\
\text { Política de Desarrollo Social estará integrado } \\
\text { por un Presidente y seis Consejeros que de- } \\
\text { berán ser ciudadanos mexicanos de recono- } \\
\text { cido prestigio en los sectores privado y social, } \\
\text { así como en los ámbitos académico y profe- } \\
\text { sional; tener experiencia mínima de diez } \\
\text { años en materia de desarrollo social, y no } \\
\text { pertenecer a algún partido político o haber } \\
\text { sido candidato a ocupar un cargo público de } \\
\text { elección popular. Serán nombrados, bajo el } \\
\text { procedimiento que determine la ley, por el } \\
\text { voto de las dos terceras partes de los miem- } \\
\text { bros presentes de la Cámara de Diputados. } \\
\text { El nombramiento podrá ser objetado por el } \\
\text { Presidente de la República en un plazo de } \\
\text { diez días hábiles y, si no lo hiciere, ocupará } \\
\text { el cargo de consejero la persona nombrada } \\
\text { por la Cámara de Diputados. Cada cuatro } \\
\text { años serán sustituidos los dos consejeros de } \\
\text { mayor antigüedad en el cargo, salvo que fue- } \\
\text { sen pospuestos y ratificados para un segundo } \\
\text { periodo. }\end{array}$ \\
\hline $\begin{array}{l}\text { Artículo } 41 . \\
\text { (fracción 1, cuarto párrafo) } \\
\text { Los partidos políticos nacionales tendrán } \\
\text { derecho a participar en las elecciones de } \\
\text { las entidades federativas y municipales. El } \\
\text { partido político nacional que no obtenga, } \\
\text { al menos, el tres por ciento de la votación } \\
\text { total emitida en cualquiera de las elec- } \\
\text { ciones que se celebren para la renovación } \\
\text { del Poder Ejecutivo o de las Cámaras del } \\
\text { Congreso de la Unión, le será cancelado el } \\
\text { registro. }\end{array}$ & $\begin{array}{l}\text { Artículo } 41 \text {. } \\
\text { (fracción 1, cuarto párrafo) } \\
\text { Los partidos políticos nacionales tendrán } \\
\text { derecho a participar en las elecciones de } \\
\text { las entidades federativas y municipales. El } \\
\text { partido político nacional que no obtenga, } \\
\text { al menos, el tres por ciento del total de la } \\
\text { votación válida emitida en cualquiera de } \\
\text { las elecciones que se celebren para la reno- } \\
\text { vación del Poder Ejecutivo o de las Cámaras } \\
\text { del Congreso de la Unión, le será cancelado } \\
\text { el registro. }\end{array}$ \\
\hline
\end{tabular}


Esta revista forma parte del acervo de la Biblioteca Jurídica Virtual del Instituto de Investigaciones Jurídicas de la UNAM

\begin{tabular}{|c|c|}
\hline $\begin{array}{l}\text { Artículo } 41 . \\
\text { VI.... } \\
\ldots \\
\ldots \\
\text { a)... } \\
\text { b) Se adquiera cobertura informativa o } \\
\text { tiempos en radio y televisión, fuera de los } \\
\text { supuestos previstos en la ley; }\end{array}$ & $\begin{array}{l}\text { Artículo } 41 . \\
\text { VI .... } \\
\ldots \\
\ldots \\
\text { a) ... } \\
\text { b) Se compre cobertura informativa o tiem- } \\
\text { pos en radio y televisión, fuera de los supues- } \\
\text { tos previstos en la ley; }\end{array}$ \\
\hline $\begin{array}{l}\text { Artículo } 54 . . . \\
\text { II. Todo partido político que alcance por lo } \\
\text { menos el tres por ciento del total de la vo- } \\
\text { tación emitida para las listas regionales de } \\
\text { las circunscripciones plurinominales, ten- } \\
\text { drá derecho a que le sean atribuidos dipu- } \\
\text { tados según el principio de representación } \\
\text { proporcional; }\end{array}$ & $\begin{array}{l}\text { Artículo } 54 \ldots \\
\text { II. Todo partido político que alcance por lo } \\
\text { menos el tres por ciento del total de la vo- } \\
\text { tación válida emitida para las listas regio- } \\
\text { nales de las circunscripciones plurinomina- } \\
\text { les, tendrá derecho a que le sean atribuidos } \\
\text { diputados según el principio de represent- } \\
\text { ación proporcional; }\end{array}$ \\
\hline $\begin{array}{l}\text { Artículo 76.... } \\
\text { I... } \\
\text { II. Ratificar los nombramientos que el } \\
\text { mismo funcionario haga de los Secretarios } \\
\text { de Estado, en caso de que éste opte por un } \\
\text { gobierno de coalición, con excepción de los } \\
\text { titulares de los Ramos de Defensa Nacional } \\
\text { y Marina; del Secretario de Relaciones; de } \\
\text { los embajadores y cónsules generales; de } \\
\text { los empleados superiores del ramo de Re- } \\
\text { laciones; de los integrantes de los órganos } \\
\text { colegiados encargados de la regulación en } \\
\text { materia de telecomunicaciones, energía, } \\
\text { competencia económica y evaluación de la } \\
\text { política de desarrollo social; y coroneles y } \\
\text { demás jefes superiores del Ejército, Armada } \\
\text { y Fuerza Aérea Nacionales, en los términos } \\
\text { que la ley disponga; } \\
\text { III a XIII.... }\end{array}$ & $\begin{array}{l}\text { Artículo } 76 . . . \\
\text { I ... } \\
\text { II. Ratificar los nombramientos que el } \\
\text { mismo funcionario haga de los Secretarios } \\
\text { de Estado, en caso de que éste opte por un } \\
\text { gobierno de coalición, con excepción de los } \\
\text { titulares de los Ramos de Defensa Nacional y } \\
\text { Marina; del Secretario de Relaciones; de los } \\
\text { embajadores y cónsules generales; de los em- } \\
\text { pleados superiores del ramo de Relaciones; } \\
\text { de los integrantes de los órganos colegiados } \\
\text { encargados de la regulación en materia de } \\
\text { telecomunicaciones, energía, competencia } \\
\text { económica, y coroneles y demás jefes superi- } \\
\text { ores del Ejército, Armada y Fuerza Aérea Na- } \\
\text { cionales, en los términos que la ley disponga; } \\
\text { III a XIII .... }\end{array}$ \\
\hline
\end{tabular}


Esta revista forma parte del acervo de la Biblioteca Jurídica Virtual del Instituto de Investigaciones Jurídicas de la UNAM

\begin{tabular}{|c|c|}
\hline $\begin{array}{l}\text { Artículo } 78 . . . \\
\ldots \\
\text { I. a IV. ... } \\
\text { V. Se deroga. } \\
\text { VI. ... } \\
\text { VII. Ratifiear los nombramientos que } \\
\text { el Presidente haga de los integrantes del } \\
\text { órgano colegiado encargado de la regu- } \\
\text { lación en materia de energía, coroneles } \\
\text { ydemás jefes strperiores del Ejéreito, Ar- } \\
\text { mada y Ftrerza Aérea Nacionales, en los } \\
\text { términos que la ley disponga, } \\
\text { VIII. ... }\end{array}$ & $\begin{array}{l}\text { Artículo } 78 \ldots \\
\ldots \\
\text { I. . a IV. ... } \\
\text { V. Se deroga. } \\
\text { VI. a VIII .... } \\
\text { (LA MODIFICACIÓN A LA FRACCIÓN } \\
\text { VIl REGRESA AL TEXTO VIGENTE). }\end{array}$ \\
\hline $\begin{array}{l}\text { Artículo } 116 \ldots \\
\ldots \\
\text { I. a III. ... } \\
\text { Fracción IV. } \\
\text { a) a e)... } \\
\text { f) ... } \\
\text { El partido político local que no obtenga, al } \\
\text { menos, el tres por ciento de la votación to- } \\
\text { tal emitida en cualquiera de las elecciones } \\
\text { que se celebren para la renovación del Po- } \\
\text { der Ejecutivo o Legislativo locales, le será } \\
\text { cancelado el registro. Esta disposición no } \\
\text { será aplicable para los partidos políticos } \\
\text { nacionales que participen en las elecciones } \\
\text { locales; }\end{array}$ & $\begin{array}{l}\text { Artículo } 116 \ldots \\
\ldots . . \\
\text { I. a III. ... } \\
\text { Fracción IV. } \\
\text { a) a e) ... } \\
\text { f) ... } \\
\text { El partido político local que no obtenga, al } \\
\text { menos, el tres por ciento de la votación to- } \\
\text { tal válida emitida en cualquiera de las elec- } \\
\text { ciones que se celebren para la renovación } \\
\text { del Poder Ejecutivo o Legislativo locales, le } \\
\text { será cancelado el registro. Esta disposición } \\
\text { no será aplicable para los partidos políticos } \\
\text { nacionales que participen en las elecciones } \\
\text { locales; }\end{array}$ \\
\hline $\begin{array}{l}\text { DÉCIMO PRIMERO.- La reforma al artí- } \\
\text { culo } 59 \text { de esta Constitución será aplicable } \\
\text { a los diputados que sean electos a partir } \\
\text { del proceso electoral de } 2015 \text {, y a los sena- } \\
\text { dores electos a partir del proceso electoral } \\
\text { de } 2018 \text {. }\end{array}$ & $\begin{array}{l}\text { DÉCIMO PRIMERO.- La reforma al artí- } \\
\text { culo } 59 \text { de esta Constitución será aplicable a } \\
\text { los diputados y senadores electos a partir } \\
\text { del proceso electoral de } 2018 \text {. }\end{array}$ \\
\hline $\begin{array}{l}\text { DÉCIMO SEGUNDO.- Las adiciones, re- } \\
\text { formas y derogaciones que se hacen a los } \\
\text { artículos } 69 \text {, párrafo tercero; } 74 \text {, fracciones } \\
111 \text { y VIl; } 76 \text {, fracciones } 11 \text { y XI; } 78 \text {, frae- } \\
\text { ción VHH, } 89 \text {, fracción } 11 \text {, párrafos segundo } \\
\text { y tercero, y fracción XVII, entrarán en vigor } \\
\text { el } 1^{\circ} \text { de diciembre de } 2018 \text {. }\end{array}$ & $\begin{array}{l}\text { DÉCIMO SEGUNDO.- Las adiciones, refor- } \\
\text { mas y derogaciones que se hacen a los artícu- } \\
\text { los } 69 \text {, párrafo tercero; } 74 \text {, fracciones } 111 \text { y } \\
\text { VIl; } 76 \text {, fracciones } 11 \text { y XI; } 89 \text {, fracción } 11 \text {, } \\
\text { párrafos segundo y tercero, y fracción XVII, } \\
\text { entrarán en vigor el1 }{ }^{\circ} \text { de diciembre de } 2018 \text {. }\end{array}$ \\
\hline
\end{tabular}


Esta revista forma parte del acervo de la Biblioteca Jurídica Virtual del Instituto de Investigaciones Jurídicas de la UNAM

DÉCIMO TERCERO.- La reforma al artículo 116 de esta Constitución en materia de reelección de diputados locales no será aplicable a los legisladores que hayan protestado el cargo en la legislatura que se encuentre en funciones a la entrada en vigor del presente Decreto.
DÉCIMO TERCERO.- La reforma al artículo 116 de esta Constitución en materia de reelección de diputados locales, así como a diputados a la Asamblea Legislativa del Distrito Federal, no será aplicable a los legisladores que hayan protestado el cargo en la legislatura que se encuentre en funciones a la entrada en vigor del presente Decreto.

\section{VIGÉSIMO PRIMERO.-}

\section{ELIMINADO}

VIGÉSIMO PRIMERO.- Los Consejeros del Instituto Federal Electoral que a la entrada en vigor del presente Decreto se encuentren en funciones, continuarán en su encargo hasta que se integre el Instituto Nacional Electoral, en términos de lo previsto por el Quinto Transitorio del presente Decreto; por lo que los actos jurídicos emitidos válidamente por el Instituto Federal Electoral en los términos de la legislación vigente, surtirán todos sus efectos legales.

SEGUNDA. Las Comisiones Unidas concordamos con el ánimo que motivó a la Cámara de Diputados a realizar cambios a la Minuta enviada por el Senado de la República, en virtud de que las aportaciones realizadas por la Cámara Revisora abonan al perfeccionamiento y consolidación de la vida democrática del país. Por ello, hacemos nuestras sus consideraciones y concordamos con los razonamientos expuestos por la Cámara de (sic) con los que justifican razonadamente los cambios realizados a la Minuta enviada por el Senado de la República.

En lo que respecta a la propuesta de que los integrantes del Consejo Nacional de Evaluación de la Política de Desarrollo Social (CONEVAL), sean nombrados por el voto de las dos terceras partes de la Cámara de Diputados, estas Comisiones Unidas estimamos procedente 
Esta revista forma parte del acervo de la Biblioteca Jurídica Virtual del Instituto de Investigaciones Jurídicas de la UNAM

la modificación realizada por la Colegisladora en virtud de que como es sabido la Cámara de Diputados está facultada para realizar la fiscalización del gasto público y la aprobación del Presupuesto de Egresos, al tiempo que es Cámara de origen respecto de los proyectos que versen sobre empréstitos, contribuciones o impuestos, además de ser ésta la que detenta la representación de la Nación.

En ese orden de ideas, estas Comisiones Unidas de dictamen coinciden con la Cámara de Diputados en cuanto a que la facultad para nombrar a los integrantes de CONEVAL debe asignarse a dicha Cámara, ya que el nuevo órgano constitucional autónomo que se propone crear, es el encargado de evaluar la política de desarrollo social, lo que implica la erogación de recursos por parte de las dependencias en beneficio de la sociedad mexicana que se encuentra en situación de vulnerabilidad. Aunado a lo anterior, que la Cámara de Diputados cuente con esta importante atribución, favorecerá el equilibrio entre las dos Cámaras integrantes del Honorable Congreso de la Unión.

TERCERA. Ahora bien, en lo que se refiere al aumento del umbral para mantener el registro como partido político, particularmente las modificaciones realizadas por la Cámara de Diputados de adicionar la expresión "del total de la votación válida emitida", en la fracción 1, cuarto párrafo, del artículo 41, en la fracción 11 del artículo 54 y en el segundo párrafo del inciso f) de la fracción IV del artículo 116 del Decreto de modificaciones constitucionales, estas Comisiones Unidas concordamos con los razonamientos expuestos por la Colegisladora, en el sentido de preferir el concepto de "votación válida emitida" para el porcentaje de los sufragios que se requieren a fin de que un partido mantenga su registro o acceda a la asignación de diputados de representación proporcional, aprovechándose la distinción de nuestro sistema electoral entre la votación total emitida, que es el número total de sufragios depositados en las urnas, incluyendo aquellos que son nulos y la votación válida emitida, pues esta última ya es el total de sufragios descontándose aquellos que fueron declarados nulos e inválidos. Por tanto, para realizar el cálculo del tres por ciento que se propone para mantener el registro y para realizar asignaciones de diputados federales y locales de representación proporcional, tendrá que hacerse sobre los votos declarados válidos.

CUARTA. En cuanto a la modificación realizada al artículo 41, fracción VI, párrafo tercero, inciso b), estas Comisiones Dictaminadoras, después de analizados los razonamientos expuestos por la Cámara de 
Esta revista forma parte del acervo de la Biblioteca Jurídica Virtual del Instituto de Investigaciones Jurídicas de la UNAM

Diputados y de valorar las implicaciones de utilizar las palabras "se compre" en sustitución de los vocablos "se adquiera", contenidos en la Minuta enviada por esta H. Cámara, coincidimos con la Cámara revisora en la pertinencia de hacer esta modificación

QUINTA. En la aprobación otorgada por el Senado la República a las modificaciones a la fracción 11 del artículo 76 constitucional se incluyeron los aspectos relativos a la ratificación de los Secretarios de Estado en la hipótesis de que el Presidente la República opte por un gobierno de coalición, con excepción de los titulares de las Secretarías de la Defensa Nacional y de Marina, así como a la ratificación del Secretario de Relaciones Exteriores en la hipótesis de que el Ejecutivo Federal cuente con mayoría de su misma formación política en las Cámaras del Congreso de la Unión o no teniéndola no opte por integrar un gobierno de coalición.

En este precepto y en la consideración de la participación de la Cámara de Senadores en el procedimiento de nombramiento de los integrantes del Consejo Nacional de Evaluación de la Política de Desarrollo Social, se incluía la previsión correspondiente en términos de la ratificación de esas designaciones por parte del Senado. Estas Comisiones Unidas estimamos pertinente la modificación hecha por la Cámara de Diputados, dado que el órgano competente y el procedimiento establecido en la propuesta de apartado C del artículo 26 constitucional se prevé la designación de los integrantes del CONEVAL en el ámbito de la Colegisladora, con el supuesto de la objeción, en suc aso, del Presidente de la República.

SEXTA. La Minuta enviada por el Senado de la República suprimió de las facultades de la Comisión Permanente, la ratificación de los nombramientos que el Presidente haga de los embajadores y cónsules generales, para que se atendieran en exclusiva por el propio Senado, habida cuenta sus atribuciones específicas en materia de política exterior.

Sin embargo y al revalorar el cúmulo de estos nombramientos durante el término de la gestión pública del Ejecutivo Federal y que pueden producirse en cualquier momento del año, a fin de no demorar la atención del Congreso a estas designaciones, coincidimos con el criterio de la H. Cámara de Diputados para que esta atribución no sea modificada.

En ese contexto, las Comisiones Unidas coincidimos con lo manifestado por la Cámara de Diputados, ya que la Comisión Permanente 
de conformidad con lo que señala la Constitución Política de los Estados Unidos Mexicanos está encargada de desahogar ciertos trámites y procesos previstos en la misma Ley Fundamental y opera en los recesos de las Cámaras del Congreso de la Unión, por tanto restarle facultades sería ir en contra de su propia naturaleza, que es coadyuvar con el desahogo de ciertas atribuciones en los recesos.

En esa tesitura, estas Comisiones Unidas acordamos la conveniencia de atender y proponer que se acepten las consideraciones de la Colegisladora realizadas al artículo 78, fracción VIl y suprimir del régimen transitorio el texto originalmente planteado para el artículo Vigésimo Primero Transitorio, así como adecuar la referencia a diversos preceptos materia de adiciones y reformas en el artículo Décimo Segundo Transitorio.

SÉPTIMA. En lo relativo a la modificación realizada por la Cámara Revisora al artículo Décimo Segundo Transitorio, consistente en la homologación del año en el que debe aplicarse la figura de la reelección legislativa consecutiva, prevista en la reforma propuesta al artículo 59 constitucional en el proyecto de Decreto, estas Comisiones Dictaminadoras estimamos pertinente la modificación planteada, en virtud de que el año propuesto por la Colegisladora, que es el 2018, coincide en la renovación total del Congreso de la Unión.

OCTAVA. En lo que respecta a la modificación realizada por la Cámara Revisora al artículo Décimo Tercero Transitorio, consistente en incluir a la Asamblea Legislativa del Distrito Federal en la previsión de que la reforma al artículo 116 constitucional en materia de reelección de diputados locales, no será aplicable a los legisladores que hayan protestado el cargo en la legislatura que se encuentre en funciones a la entrada en vigor del Decreto de reformas y adiciones a la Constitución Política de los Estados Unidos Mexicanos, en materia políticaelectoral.

Estas Comisiones Unidas coincidimos con la Colegisladora en ese respecto, ya que no se había considerado a los integrantes de la Asamblea Legislativa del Distrito Federal, lo que podía causar una desigualdad entre los Estados y el Distrito Federal en la aplicación de la modificación constitucional planteada para hacer factible la reelección consecutiva de diputados locales.

NOVENA. La Cámara de Diputados adicionó un artículo Vigésimo Primero Transitorio al proyecto de Decreto, en el que se establece que los Consejeros del Instituto Federal Electoral que se encuentren en 
funciones a la entrada en vigor del decreto de reformas a la Constitución Política de los Estados Unidos Mexicanos en materia políticaelectoral, continuarán en su encargo hasta que se integre el Instituto Nacional Electoral, señalándose que los actos jurídicos emitidos válidamente por el Instituto Federal Electoral surtirán todos sus efectos legales.

Estas Comisiones Unidas, estimamos relevante esta modificación, ya que brinda seguridad jurídica y certeza a los actos realizados por estos servidores públicos del Instituto Federal Electoral durante la transición de una institución a otra; lo anterior sin demérito de la previsión de la permanencia de los consejeros en el encargo, en tanto no se integre el nuevo organismo electoral nacional.

DÉCIMA. Ahora bien, resulta de primera importancia referir al proceso legislativo que dispone el artículo 72, párrafo E de la Constitución Política de los Estados Unidos Mexicanos, que se transcribe a continuación:

Artículo 72. Todo proyecto de ley o decreto, cuya resolución no sea exclusiva de alguna de las Cámaras, se discutirá sucesivamente en ambas, observándose la Ley del Congreso y sus reglamentos respectivos, sobre la forma, intervalos y modo de proceder en las discusiones $y$ votaciones:

a) a d) ....

e) Si un proyecto de ley o decreto fuese desechado en parte, o modificado, o adicionado por la Cámara revisora, la nueva discusión de la Cámara de su origen versará únicamente sobre lo desechado o sobre las reformas o adiciones, sin poder alterarse en manera alguna los artículos aprobados. Si las adiciones o reformas hechas por la Cámara revisora fuesen aprobadas por la mayoría absoluta de los votos presentes en la Cámara de su origen, se pasará todo el proyecto al Ejecutivo, para los efectos de la fracción a). Si las adiciones o reformas hechas por la Cámara revisora fueren reprobadas por la mayoría de votos en la Cámara de su origen, volverán a aquella para que tome en consideración las razones de ésta, y si por mayoría absoluta de votos presentes se desecharen en esta segunda revisión dichas adiciones o reformas, el proyecto, en lo que haya sido aprobado por ambas Cámaras, se pasará al Ejecutivo para los efectos de la fracción a). Si la Cámara revisora insistiere, por la mayoría absoluta de votos presentes, en dichas adiciones o reformas, todo el proyecto 
no volverá a presentarse sino hasta el siguiente período de sesiones, a no ser que ambas Cámaras acuerden, por la mayoría absoluta de sus miembros presentes, que se expida la ley o decreto sólo con los artículos aprobados, y que se reserven los adicionados o reformados para su examen y votación en las sesiones siguientes.

f). a j)....

Del precepto constitucional transcrito, se colige que la presente discusión en esta Cámara de origen del proyecto de Decreto que nos ocupa, sólo ha de versar sobre los textos en los cuales la Cámara Revisora ha adoptado una decisión que difiere de la propuesta que les fue remitida; a su vez, el precepto transcrito implica que de aprobarse las modificaciones hechas por la Cámara Revisora, puede seguir su curso legal, el cual, por tratarse de una reforma a la Constitución Política de los Estados Unidos Mexicanos, el paso siguiente es remitirla a las Legislaturas de los Estados, en términos de lo que dispone el artículo 135 de la Ley Fundamental, que establece:

\section{Artículo 135. La presente Constitución puede ser adicionada o} reformada. Para que las adiciones o reformas lleguen a ser parte de la misma, se requiere que el Congreso de la Unión, por el voto de las dos terceras partes de los individuos presentes, acuerden las reformas o adiciones, y que éstas sean aprobadas por la mayoría de las legislaturas de los Estados.

El Congreso de la Unión o la Comisión Permanente en su caso, harán el cómputo de los votos de las Legislaturas y la declaración de haber sido aprobadas las adiciones o reformas.

UNDÉCIMA. En este tenor, las Comisiones Dictaminadoras están conscientes de la importancia de esta trascendental reforma constitucional en la citada materia, pues representa un valioso avance democrático para la vida institucional de nuestro país.

Por tanto, estas Comisiones Unidas del Senado de la República, hacemos nuestros los argumentos de la Cámara de Diputados y en consecuencia consideramos de la mayor importancia que estas reformas continúen el proceso legislativo previsto en la Constitución Política de los Estados Unidos Mexicanos, remitiéndose los textos aprobados en el ámbito del Congreso de la Unión a las legislaturas de los Estados, tal y como lo señala el artículo antes transcrito. 
Esta revista forma parte del acervo de la Biblioteca Jurídica Virtual del Instituto de Investigaciones Jurídicas de la UNAM

En términos de lo expuesto y sobre la base de la función constitucional que en el caso específico corresponde a estas Comisiones Unidas y en su oportunidad al Pleno Senatorial, se propone la aprobación del proyecto de dictamen que se ha puesto a la consideración.

\section{TEXTO NORMATIVO Y RÉGIMEN TRANSITORIO}

Por lo anteriormente expuesto y fundado, las Comisiones Unidas de Puntos Constitucionales, de Gobernación, de Reforma del Estado y de Estudios Legislativos, Primera y Segunda conforme a las facultades que le confieren los artículos 85, numeral 2, inciso a); 86, 89 y 94 de la Ley Orgánica del Congreso General de los Estados Unidos Mexicanos; así como los artículos 113, 117, 135, 178, 182, 188, 190, 220 y 221 del Reglamento del Senado de la República, sometemos a la consideración del Pleno la aprobación del siguiente Proyecto de Decreto que reforma y adiciona diversas disposiciones de la Constitución Política de los Estados Unidos Mexicanos, en materia político-electoral:

ÚNICO. Se reforman los párrafos segundo y cuarto del apartado A del artículo 26; la fracción Vil del párrafo vigésimo segundo del artículo 28; el primer párrafo del artículo 29; la fracción VIl y los numerales $4^{\circ}$ y $6^{\circ}$ de la fracción VIII del artículo 35; la base 1 en sus párrafos inicial y segundo, el tercer párrafo de la base 11, la base 111 en su párrafo inicial, el apartado A en su párrafo inicial e incisos a), e), e) y g) y en su segundo párrafo, el apartado $B$ en su primer párrafo e inciso e) y su segundo párrafo, el apartado $C$ en su primer párrafo y el apartado D, la base IV en su párrafo inicial y la base $\mathrm{V}$ del artículo 41; la fracción 11 del artículo 54; el segundo párrafo de la fracción $\mathrm{V}$ del artículo 55; el artículo 59; el primer párrafo del artículo 65; el segundo párrafo del artículo 69; el inciso a) de la fracción XXI del artículo 73; el tercer párrafo de la fracción IV del artículo 74; la fracción 11 del artículo 76; la fracción VI del artículo 82; el artículo 83; el segundo párrafo del artículo 84; la fracción IX del artículo 89, el segundo párrafo del artículo 93; la fracción VI del artículo 95; las fracciones VIl y VIII del artículo 99; el apartado A del artículo 102; los incisos e) y f) del segundo párrafo de la fracción 11 y la fracción 111 del artículo 105; el segundo párrafo de la fracción $\mathrm{V}$, el segundo párrafo de la fracción VIII, los párrafos primero y tercero de la fracción XIII y la fracción XV del artículo 107, el primer párrafo del artículo 11 O, el primer párrafo 
del artículo 111; el encabezado y el segundo párrafo de la fracción 1 del artículo 115; los párrafos segundo y tercero de la fracción 11, el primer párrafo y los incisos a), b), e), d), h), j), k) y n) de la fracción IV del artículo 116; el segundo párrafo del artículo 119, la fracción 111 de la BASE PRIMERA del apartado C del artículo 122; y se adicionan un aparado $\mathrm{C}$ al artículo 26; un cuarto párrafo a la base 1 y un tercer, cuarto y quinto párrafos de la base VI del artículo 41, un tercer párrafo al artículo 69; la fracción XXIX-U al artículo 73; las fracciones 111 y VIl al artículo 74; las fracciones XI y XII, recorriéndose la subsecuente en su orden, al artículo 76; un segundo y tercer párrafos a la fracción 11 y la fracción XVII al artículo 89; los párrafos tercero y cuarto al artículo 90; la fracción IX, recorriéndose la subsecuente en su orden, al artículo 99; un inciso h) al segundo párrafo de la fracción 11 del artículo 1 05; un segundo párrafo al inciso f) de la fracción IV, así como una fracción VIII al artículo 116; de la Constitución Política de los Estados Unidos Mexicanos, para quedar como sigue:

\section{Artículo 26.}

A ...

Los fines del proyecto nacional contenidos en esta Constitución determinarán los objetivos de la planeación. La planeación será democrática y deliberativa. Mediante los mecanismos de participación que establezca la ley, recogerá las aspiraciones y demandas de la sociedad para incorporarlas al plan y los programas de desarrollo. Habrá un plan nacional de desarrollo al que se sujetarán obligatoriamente los programas de la Administración Pública Federal.

En el sistema de planeación democrática y deliberativa, el Congreso de la Unión tendrá la intervención que señale la ley.

B ....

C. El Estado contará con un Consejo Nacional de Evaluación de la Política de Desarrollo Social, que será un órgano autónomo, con personalidad jurídica y patrimonio propios, a cargo de la medición de la pobreza y de la evaluación de los programas, objetivos, metas y acciones de la política de desarrollo social, así como de emitir recomendaciones en los términos que disponga la ley, la cual establecerá las formas de coordinación del órgano con las autoridades federales, locales y municipales para el ejercicio de sus funciones. 
El Consejo Nacional de Evaluación de la Política de Desarrollo Social estará integrado por un Presidente y seis Consejeros que deberán ser ciudadanos mexicanos de reconocido prestigio en los sectores privado y social, así como en los ámbitos académico y profesional; tener experiencia mínima de diez años en materia de desarrollo social, y no pertenecer a algún partido político o haber sido candidato a ocupar un cargo público de elección popular. Serán nombrados, bajo el procedimiento que determine la ley, por el voto de las dos terceras partes de los miembros presentes de la Cámara de Diputados. El nombramiento podrá ser objetado por el Presidente de la República en un plazo de diez días hábiles y, si no lo hiciere, ocupará el cargo de consejero la persona nombrada por la Cámara de Diputados. Cada cuatro años serán sustituidos los dos consejeros de mayor antigüedad en el cargo, salvo que fuesen propuestos y ratificados para un segundo período.

El Presidente del Consejo Nacional de Evaluación de la Política de Desarrollo Social será elegido en los mismos términos del párrafo anterior. Durará en su encargo cinco años, podrá ser reelecto por una sola vez y sólo podrá ser removido de sus funciones en los términos del Título Cuarto de esta Constitución.

El Presidente del Consejo Nacional de Evaluación de la Política de Desarrollo Social presentará anualmente a los Poderes de la Unión un informe de actividades. Comparecerá ante las Cámaras del Congreso en los términos que disponga la ley.

\section{Artículo 28 ....}

\section{1. a VI....}

VIl. No haber sido Secretario de Estado, Fiscal General de la República, senador, diputado federal o local, Gobernador de algún Estado o Jefe de Gobierno del Distrito Federal, durante el año previo a su nombramiento, $\mathrm{y}$ 
VIII. ...

...

Artículo 29. En los casos de invasión, perturbación grave de la paz pública, o de cualquier otro que ponga a la sociedad en grave peligro o conflicto, solamente el Presidente de los Estados Unidos Mexicanos, con la aprobación del Congreso de la Unión o de la Comisión Permanente cuando aquel no estuviere reunido, podrá restringir o suspender en todo el país o en lugar determinado el ejercicio de los derechos y las garantías que fuesen obstáculo para hacer frente, rápida y fácilmente a la situación; pero deberá hacerlo por un tiempo limitado, por medio de prevenciones generales y sin que la restricción o suspensión se contraiga a determinada persona. Si la restricción o suspensión tuviese lugar hallándose el Congreso reunido, éste concederá las autorizaciones que estime necesarias para que el Ejecutivo haga frente a la situación; pero si se verificase en tiempo de receso, se convocará de inmediato al Congreso para que las acuerde.

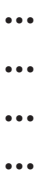

Artículo 35....

1 a VI. ...

VII. Iniciar leyes, en los términos y con los requisitos que señalen esta Constitución y la Ley del Congreso. El Instituto Nacional Electoral tendrá las facultades que en esta materia le otorgue la ley, y

VIII. ...

$1^{\circ}$. a $3^{\circ}$....

$4^{\circ}$. El Instituto Nacional Electoral tendrá a su cargo, en forma directa, la verificación del requisito establecido en el inciso e) del apartado 1 o de la presente fracción, así como la organización, desarrollo, cómputo y declaración de resultados;

$5^{\circ}$....

$6^{\circ}$. Las resoluciones del Instituto Nacional Electoral podrán ser impugnadas en los términos de lo dispuesto en la fracción VI del artículo 41, así como de la fracción 111 del artículo 99 de esta Constitución; y 
Esta revista forma parte del acervo de la Biblioteca Jurídica Virtual del Instituto de Investigaciones Jurídicas de la UNAM

$7^{\circ}$...

Artículo 41....

I. Los partidos políticos son entidades de interés público; la ley determinará las normas y requisitos para su registro legal, las formas específicas de su intervención en el proceso electoral y los derechos, obligaciones y prerrogativas que les corresponden.

Los partidos políticos tienen como fin promover la participación del pueblo en la vida democrática, contribuir a la integración de los órganos de representación política y como organizaciones de ciudadanos, hacer posible el acceso de éstos al ejercicio del poder público, de acuerdo con los programas, principios e ideas que postulan y mediante el sufragio universal, libre, secreto y directo, así como las reglas para garantizar la paridad entre los géneros, en candidaturas a legisladores federales y locales. Sólo los ciudadanos podrán formar partidos políticos y afiliarse libre e individualmente a ellos; por tanto, quedan prohibidas la intervención de organizaciones gremiales o con objeto social diferente en la creación de partidos y cualquier forma de afiliación corporativa.

Los partidos políticos nacionales tendrán derecho a participar en las elecciones de las entidades federativas y municipales. El partido político nacional que no obtenga, al menos, el tres por ciento del total de la votación válida emitida en cualquiera de las elecciones que se celebren para la renovación del Poder Ejecutivo o de las Cámaras del Congreso de la Unión, le será cancelado el registro.

II. ...

a) a c) $\ldots$

La ley fijará los límites a las erogaciones en los procesos internos de selección de candidatos y en las campañas electorales. La propia ley establecerá el monto máximo que tendrán las aportaciones de sus militantes y simpatizantes; ordenará los procedimientos para el control, fiscalización oportuna y vigilancia, durante la campaña, del origen y uso de todos los recursos con que cuenten; asimismo, dispondrá las sanciones que deban imponerse por el incumplimiento de estas disposiciones. 
III. Los partidos políticos nacionales tendrán derecho al uso de manera permanente de los medios de comunicación social. Los candidatos independientes tendrán derecho de acceso a prerrogativas para las campañas electorales en los términos que establezca la ley.

Apartado A. El Instituto Nacional Electoral será autoridad única para la administración del tiempo que corresponda al Estado en radio y televisión destinado a sus propios fines y al ejercicio del derecho de los partidos políticos nacionales, de acuerdo con lo siguiente y a lo que establezcan las leyes:

a) A partir del inicio de las precampañas y hasta el día de la jornada electoral quedarán a disposición del Instituto Nacional Electoral cuarenta y ocho minutos diarios, que serán distribuidos en dos y hasta tres minutos por cada hora de transmisión en cada estación de radio y canal de televisión, en el horario referido en el inciso d) de este apartado. En el período comprendido entre el fin de las precampañas y el inicio de las campañas, el cincuenta por ciento de los tiempos en radio y televisión se destinará a los fines propios de las autoridades electorales, y el resto a la difusión de mensajes genéricos de los partidos políticos, conforme a lo que establezca la ley;

b) ...

c) Durante las campañas electorales deberá destinarse para cubrir el derecho de los partidos políticos y los candidatos al menos el ochenta y cinco por ciento del tiempo

total disponible a que se refiere el inciso a) de este apartado;

d) ...

e) El tiempo establecido como derecho de los partidos políticos y, en su caso, de los candidatos independientes, se distribuirá entre los mismos conforme a lo siguiente: el setenta por ciento será distribuido entre los partidos políticos de acuerdo a los resultados de la elección para diputados federales inmediata anterior y el treinta por ciento restante será dividido en partes iguales, de las cuales, hasta una de ellas podrá ser asignada a los candidatos independientes en su conjunto;

f) ...

g) Con independencia de lo dispuesto en los apartados A y B de esta base y fuera de los períodos de precampañas y campañas electorales federales, al Instituto Nacional Electoral le será asignado hasta el doce por ciento del tiempo total de que el Estado disponga en radio y televisión, conforme a las leyes y bajo cualquier modalidad; del total asignado, el Instituto distribuirá entre los partidos políticos naciona- 
les en forma igualitaria un cincuenta por ciento; el tiempo restante lo utilizará para fines propios o de otras autoridades electorales, tanto federales como de las entidades federativas. Cada partido político nacional utilizará el tiempo que por este concepto le corresponda en los formatos que establezca la ley. En todo caso, las transmisiones a que se refiere este inciso se harán en el horario que determine el Instituto conforme a lo señalado en el inciso d) del presente Apartado. En situaciones especiales, el Instituto podrá disponer de los tiempos correspondientes a mensajes partidistas a favor de un partido político, cuando así se justifique.

Los partidos políticos y los candidatos en ningún momento podrán contratar o adquirir, por sí o por terceras personas, tiempos en cualquier modalidad de radio y televisión.

Apartado B. Para fines electorales en las entidades federativas, el Instituto Nacional Electoral administrará los tiempos que correspondan al Estado en radio y televisión en las estaciones y canales de cobertura en la entidad de que se trate, conforme a lo siguiente y a lo que determine la ley:

a) y b) ...

c) La distribución de los tiempos entre los partidos políticos, incluyendo a los de registro local, y los candidatos independientes se realizará de acuerdo con los criterios señalados en el apartado A de esta base y lo que determine la legislación aplicable.

Cuando a juicio del Instituto Nacional Electoral el tiempo total en radio y televisión a que se refieren este apartado y el anterior fuese insuficiente para sus propios fines, los de otras autoridades electorales o para los candidatos independientes, determinará lo conducente para cubrir el tiempo faltante, conforme a las facultades que la ley le confiera.

Apartado C. En la propaganda política o electoral que difundan los partidos y candidatos deberán abstenerse de expresiones que calumnien a las personas.

Apartado D. El Instituto Nacional Electoral, mediante procedimientos expeditos en los términos de la ley, investigará las infracciones a lo dispuesto en esta Base e integrará el expediente para someterlo al conocimiento y resolución del Tribunal Electoral del Poder Judicial de 
la Federación. En el procedimiento, el Instituto podrá imponer, entre otras medidas cautelares, la orden de suspender o cancelar de manera inmediata las transmisiones en radio y televisión, de conformidad con lo que disponga la ley.

IV. La ley establecerá los requisitos y las formas de realización de los procesos de selección y postulación de candidatos a cargos de elección popular, así como las reglas para las precampañas y las campañas electorales.

V. La organización de las elecciones es una función estatal que se realiza a través del Instituto Nacional Electoral y de los organismos públicos locales, en los términos que establece esta Constitución.

Apartado A. El Instituto Nacional Electoral es un organismo público autónomo dotado de personalidad jurídica y patrimonio propios, en cuya integración participan el Poder Legislativo de la Unión, los partidos políticos nacionales y los ciudadanos, en los términos que ordene la ley. En el ejercicio de esta función estatal, la certeza, legalidad, independencia, imparcialidad, máxima publicidad y objetividad serán principios rectores.

El Instituto Nacional Electoral será autoridad en la materia, independiente en sus decisiones y funcionamiento, y profesional en su desempeño; contará en su estructura con órganos de dirección, ejecutivos, técnicos y de vigilancia. El Consejo General será su órgano superior de dirección y se integrará por un consejero Presidente y diez consejeros electorales, y concurrirán, con voz pero sin voto, los consejeros del Poder Legislativo, los representantes de los partidos políticos y un Secretario Ejecutivo; la ley determinará las reglas para la organización y funcionamiento de los órganos, las relaciones de mando entre éstos, así como la relación con los organismos públicos locales. Los órganos ejecutivos y técnicos dispondrán del personal calificado necesario para el ejercicio de sus atribuciones. Una Contraloría General tendrá a su cargo, con autonomía técnica y de gestión, la fiscalización de todos los ingresos y egresos del Instituto. Las disposiciones de la ley electoral y del Estatuto que con base en ella apruebe el Consejo General, regirán las relaciones de trabajo con los servidores del organismo público. Los órganos de vigilancia del padrón electoral se integrarán mayoritariamente por representantes de los partidos polí- 
ticos nacionales. Las mesas directivas de casilla estarán integradas por ciudadanos.

Las sesiones de todos los órganos colegiados de dirección serán públicas en los términos que señale la ley.

El Instituto contará con una oficialía electoral investida de fe pública para actos de naturaleza electoral, cuyas atribuciones y funcionamiento serán reguladas por la ley.

El consejero Presidente y los consejeros electorales durarán en su cargo nueve años y no podrán ser reelectos. Serán electos por el voto de las dos terceras partes de los miembros presentes de la Cámara de Diputados, mediante el siguiente procedimiento:

a) La Cámara de Diputados emitirá el acuerdo para la elección del consejero Presidente y los consejeros electorales, que contendrá la convocatoria pública, las etapas completas para el procedimiento, sus fechas límites y plazos improrrogables, así como el proceso para la designación de un comité técnico de evaluación, integrado por siete personas de reconocido prestigio, de las cuales tres serán nombradas por el órgano de dirección política de la Cámara de Diputados, dos por la Comisión Nacional de los Derechos Humanos y dos por el organismo garante establecido en el artículo 6o. de esta Constitución;

b) El comité recibirá la lista completa de los aspirantes que concurran a la convocatoria pública, evaluará el cumplimiento de los requisitos constitucionales y legales, así como su idoneidad para desempeñar el cargo; seleccionará a los mejor evaluados en una proporción de cinco personas por cada cargo vacante, y remitirá la relación correspondiente al órgano de dirección política de la Cámara de Diputados;

c) El órgano de dirección política impulsará la construcción de los acuerdos para la elección del consejero Presidente y los consejeros electorales, a fin de que una vez realizada la votación por este órgano en los términos de la ley, se remita al Pleno de la Cámara la propuesta con las designaciones correspondientes;

d) Vencido el plazo que para el efecto se establezca en el acuerdo a que se refiere el inciso a), sin que el órgano de dirección política de la Cámara haya realizado la votación o remisión previstas en el inciso anterior, o habiéndolo hecho, no se alcance la votación requerida en el Pleno, se deberá convocar a éste a una sesión en la que se realizará la elección mediante insaculación de la lista conformada por el comité de evaluación; 
e) Al vencimiento del plazo fijado en el acuerdo referido en el inciso a), sin que se hubiere concretado la elección en los términos de los incisos e) y d), el Pleno de la Suprema Corte de Justicia de la Nación realizará, en sesión pública, la designación mediante insaculación de la lista conformada por el comité de evaluación.

De darse la falta absoluta del consejero Presidente o de cualquiera de los consejeros electorales durante los primeros seis años de su encargo, se elegirá un sustituto para concluir el período de la vacante. Si la falta ocurriese dentro de los últimos tres años, se elegirá a un consejero para un nuevo periodo.

El consejero Presidente y los consejeros electorales no podrán tener otro empleo, cargo o comisión, con excepción de aquellos en que actúen en representación del Consejo General y los no remunerados que desempeñen en asociaciones docentes, científicas, culturales, de investigación o de beneficencia.

El titular de la Contraloría General del Instituto será designado por la Cámara de Diputados con el voto de las dos terceras partes de sus miembros presentes a propuesta de instituciones públicas de educación superior, en la forma y términos que determine la ley.

Durará seis años en el cargo y podrá ser reelecto por una sola vez. Estará adscrito administrativamente a la presidencia del Consejo General y mantendrá la coordinación técnica necesaria con la entidad de fiscalización superior de la Federación.

El Secretario Ejecutivo será nombrado con el voto de las dos terceras partes del Consejo General a propuesta de su Presidente.

La ley establecerá los requisitos que deberán reunir para su designación el consejero Presidente del Consejo General, los consejeros electorales, el Contralor General y el Secretario Ejecutivo del Instituto Nacional Electoral. Quienes hayan fungido como consejero Presidente, consejeros electorales y Secretario Ejecutivo no podrán desempeñar cargos en los poderes públicos en cuya elección hayan participado, de dirigencia partidista, ni ser postulados a cargos de elección popular, durante los dos años siguientes a la fecha de conclusión de su encargo.

Los consejeros del Poder Legislativo serán propuestos por los grupos parlamentarios con afiliación de partido en alguna de las Cámaras. Sólo habrá un Consejero por cada grupo parlamentario no obstante su reconocimiento en ambas Cámaras del Congreso de la Unión.

Apartado B. Corresponde al Instituto Nacional Electoral en los términos que establecen esta Constitución y las leyes: 
a) Para los procesos electorales federales y locales:

1. La capacitación electoral;

2. La geografía electoral, así como el diseño y determinación de los distritos electorales y división del territorio en secciones electorales;

3. El padrón y la lista de electores;

4. La ubicación de las casillas y la designación de los funcionarios de sus mesas directivas;

5. Las reglas, lineamientos, criterios y formatos en materia de resultados preliminares; encuestas o sondeos de opinión; observación electoral; conteos rápidos; impresión de documentos y producción de materiales electorales;

6. La fiscalización de los ingresos y egresos de los partidos políticos y candidatos, y

7. Las demás que determine la ley.

b) Para los procesos electorales federales:

1. Los derechos y el acceso a las prerrogativas de los candidatos y partidos políticos;

2. La preparación de la jornada electoral;

3. La impresión de documentos y la producción de materiales electorales;

4. Los escrutinios y cómputos en los términos que señale la ley;

5. La declaración de validez y el otorgamiento de constancias en las elecciones de diputados y senadores;

6. El cómputo de la elección de Presidente de los Estados Unidos Mexicanos en cada uno de los distritos electorales uninominales, $y$

7. Las demás que determine la ley.

El Instituto Nacional Electoral asumirá mediante convenio con las autoridades competentes de las entidades federativas que así lo soliciten, la organización de procesos electorales locales, en los términos que disponga la legislación aplicable. A petición de los partidos políticos y con cargo a sus prerrogativas, en los términos que establezca la ley, podrá organizar las elecciones de sus dirigentes.

La fiscalización de las finanzas de los partidos políticos y de las campañas de los candidatos estará a cargo del Consejo General del Instituto Nacional Electoral. La ley desarrollará las atribuciones del Consejo para la realización de dicha función, así como la definición de los órganos técnicos dependientes del mismo, responsables de realizar las revisiones e instruir los procedimientos para la aplicación de las sanciones correspondientes. En el cumplimiento de sus atribucio- 
nes, el Consejo General no estará limitado por los secretos bancario, fiduciario y fiscal, y contará con el apoyo de las autoridades federales y locales.

En caso de que el Instituto Nacional Electoral delegue la función de fiscalización, su órgano técnico será el conducto para superar la limitación a que se refiere el párrafo anterior.

Apartado C. En las entidades federativas las elecciones locales estarán a cargo de organismos públicos locales en los términos de esta Constitución, que ejercerán funciones en las siguientes materias:

1. Derechos y el acceso a las prerrogativas de los candidatos y partidos políticos;

2. Educación cívica;

3. Preparación de la jornada electoral;

4. Impresión de documentos y la producción de materiales electorales;

5. Escrutinios y cómputos en los términos que señale la ley;

6. Declaración de validez y el otorgamiento de constancias en las elecciones locales;

7. Cómputo de la elección del titular del poder ejecutivo;

8. Resultados preliminares; encuestas o sondeos de opinión; observación electoral, y conteos rápidos, conforme a los lineamientos establecidos en el Apartado anterior;

9. Organización, desarrollo, cómputo y declaración de resultados en los mecanismos de participación ciudadana que prevea la legislación local;

10. Todas las no reservadas al Instituto Nacional Electoral, y

11. Las que determine la ley.

En los supuestos que establezca la ley y con la aprobación de una mayoría de cuando menos ocho votos del Consejo General, el Instituto Nacional Electoral podrá:

a) Asumir directamente la realización de las actividades propias de la función electoral que corresponden a los órganos electorales locales;

b) Delegar en dichos órganos electorales las atribuciones a que se refiere el inciso a) del Apartado B de esta Base, sin perjuicio de reasumir su ejercicio directo en cualquier momento, o

c) Atraer a su conocimiento cualquier asunto de la competencia de los órganos electorales locales, cuando su trascendencia así lo amerite o para sentar un criterio de interpretación. 
Corresponde al Instituto Nacional Electoral designar y remover a los integrantes del órgano superior de dirección de los organismos públicos locales, en los términos de esta Constitución.

Apartado D. El Servicio Profesional Electoral Nacional comprende la selección, ingreso, capacitación, profesionalización, promoción, evaluación, rotación, permanencia y disciplina, de los servidores públicos de los órganos ejecutivos y técnicos del Instituto Nacional Electoral y de los organismos públicos locales de las entidades federativas en materia electoral. El Instituto Nacional Electoral regulará la organización y funcionamiento de este Servicio.

VI. ...

La ley establecerá el sistema de nulidades de las elecciones federales o locales por violaciones graves, dolosas y determinantes en los siguientes casos:

a) Se exceda el gasto de campaña en un cinco por ciento del monto total autorizado;

b) Se compre cobertura informativa o tiempos en radio y televisión, fuera de los supuestos previstos en la ley;

c) Se reciban o utilicen recursos de procedencia ilícita o recursos públicos en las campañas;

Dichas violaciones deberán acreditarse de manera objetiva y material. Se presumirá que las violaciones son determinantes cuando la diferencia entre la votación obtenida entre el primero y el segundo lugar sea menor al cinco por ciento.

En caso de nulidad de la elección, se convocará a una elección extraordinaria, en la que no podrá participar la persona sancionada.

\section{Artículo 54 ....}

I. ...

III. Todo partido político que alcance por lo menos el tres por ciento del total de la votación válida emitida para las listas regionales de las circunscripciones plurinominales, tendrá derecho a que le sean atribuidos diputados según el principio de representación proporcional;

III. a VI. ...

Artículo 55. ...

I. a IV. ...

V....

No ser Ministro de la Suprema Corte de Justicia de la Nación, ni Magistrado, ni Secretario del Tribunal Electoral del Poder Judicial de 
la Federación, ni Consejero Presidente o consejero electoral en los consejos General, locales o distritales del Instituto Nacional Electoral, ni Secretario Ejecutivo, Director Ejecutivo o personal profesional directivo del propio Instituto, salvo que se hubiere separado de su encargo, de manera definitiva, tres años antes del día de la elección.

\section{VI. y VII. ...}

Artículo 59. Los Senadores podrán ser electos hasta por dos periodos consecutivos y los Diputados al Congreso de la Unión hasta por cuatro periodos consecutivos. La postulación sólo podrá ser realizada por el mismo partido o por cualquiera de los partidos integrantes de la coalición que los hubieren postulado, salvo que hayan renunciado o perdido su militancia antes de la mitad de su mandato.

Artículo 65. El Congreso se reunirá a partir del $1^{\circ}$ de septiembre de cada año para celebrar un primer periodo de sesiones ordinarias, excepto cuando el Presidente de la República inicie su encargo en la fecha prevista en el artículo 83 de esta Constitución, en cuyo caso se reunirá a partir del $1^{\circ}$ de agosto; y a partir del $1^{\circ}$ de febrero para celebrar un segundo periodo de sesiones ordinarias.

\section{Artículo 69....}

Cada una de las Cámaras realizará el análisis del informe y podrá solicitar al Presidente de la República ampliar la información mediante pregunta por escrito y citar a los Secretarios de Estado y a los directores de las entidades paraestatales, quienes comparecerán y rendirán informes bajo protesta de decir verdad. La Ley del Congreso y sus reglamentos regularán el ejercicio de esta facultad.

En el primer año de su mandato, en la apertura del segundo periodo de sesiones ordinarias del Congreso, el Presidente de la República presentará ante la Cámara de Senadores, para su aprobación, la Estrategia Nacional de Seguridad Pública e informará anualmente sobre el estado que guarde.

Artículo 73....

\section{I. a XX....}

XXI....

a) Las leyes generales en materias de secuestro, trata de personas y delitos electorales, que establezcan como mínimo, los tipos penales y sus sanciones.

b) у C) ... 
-...

XXII. a XXIX-T. ...

XXIX-U. Para expedir las leyes generales que distribuyan competencias entre la Federación y las entidades federativas en materias de partidos políticos; organismos electorales, y procesos electorales, conforme a las bases previstas en esta Constitución.

XXX....

Artículo 74....

I y II. ...

III. Ratificar el nombramiento que el Presidente de la República haga del Secretario del ramo en materia de Hacienda, salvo que se opte por un gobierno de coalición, en cuyo caso se estará a lo dispuesto en la fracción 11 del artículo 76 de esta Constitución; así como de los demás empleados superiores de Hacienda;

IV. ...

Cuando inicie su encargo en la fecha prevista por el artículo 83, el Ejecutivo Federal hará llegar a la Cámara la iniciativa de Ley de Ingresos y el proyecto de Presupuesto de Egresos de la Federación a más tardar el día 15 del mes de noviembre.

V. y VI. ...

VII. Aprobar el Plan Nacional de Desarrollo en el plazo que disponga la ley. En caso de que la Cámara de Diputados no se pronuncie en dicho plazo, el Plan se entenderá aprobado;

VIII....

Artículo 76. ...

I. ...

II. Ratificar los nombramientos que el mismo funcionario haga de los Secretarios de Estado, en caso de que éste opte por un gobierno de coalición, con excepción de los titulares de los ramos de Defensa Nacional y Marina; del Secretario de Relaciones; de los embajadores y cónsules generales; de los empleados superiores del ramo de Relaciones; de los integrantes de los órganos colegiados encargados de la regulación en materia de telecomunicaciones, energía, competencia económica, y coroneles y demás jefes superiores del Ejército, Armada y Fuerza Aérea Nacionales, en los términos que la ley disponga; 
III. a X....

XI. Aprobar la Estrategia Nacional de Seguridad Pública en el plazo que disponga la ley. En caso de que el Senado no se pronuncie en dicho plazo, ésta se entenderá aprobada;

XII. Integrar la lista de candidatos a Fiscal General de la República; nombrar a dicho servidor público, y formular objeción a la remoción que del mismo haga el Ejecutivo Federal, de conformidad con el artículo 102, Apartado A, de esta Constitución, y XIII. Las demás que la misma Constitución le atribuya.

Artículo 78....

I. a IV. ...

V. Se deroga.

VI. a VIII. ...

Artículo 82....

1. a V. ...

VI. No ser Secretario o subsecretario de Estado, Fiscal General de la República, Gobernador de algún estado ni Jefe de Gobierno del Distrito Federal, a menos de que se separe de su puesto seis meses antes del día de la elección; y

VII....

Artículo 83. El Presidente entrará a ejercer su encargo el $1^{\circ}$ de octubre y durará en él seis años. El ciudadano que haya desempeñado el cargo de Presidente de la República, electo popularmente, o con el carácter de interino o sustituto, o asuma provisionalmente la titularidad del Ejecutivo Federal, en ningún caso y por ningún motivo podrá volver a desempeñar ese puesto.

\section{Artículo 84....}

Quien ocupe provisionalmente la Presidencia no podrá remover o designar a los Secretarios de Estado sin autorización previa de la Cámara de Senadores. Asimismo, entregará al Congreso de la Unión un informe de labores en un plazo no mayor a diez días, contados a partir del momento en que termine su encargo.

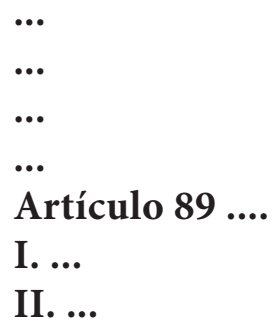


Los Secretarios de Estado y los empleados superiores de Hacienda y de Relaciones entrarán en funciones el día de su nombramiento. Cuando no sean ratificados en los términos de esta Constitución, dejarán de ejercer su encargo.

En los supuestos de la ratificación de los Secretarios de Relaciones y Hacienda, cuando no se opte por un gobierno de coalición, si la Cámara respectiva no ratificare en dos ocasiones el nombramiento del mismo Secretario de Estado, ocupará el cargo la persona que designe el Presidente de la República;

\section{III. a VIII. ...}

IX. Intervenir en la designación del Fiscal General de la República y removerlo, en términos de lo dispuesto en el artículo 102, Apartado A, de esta Constitución;

\section{X a XVI....}

XVII. En cualquier momento, optar por un gobierno de coalición con uno o varios de los partidos políticos representados en el Congreso de la Unión.

El gobierno de coalición se regulará por el convenio y el programa respectivos, los cuales deberán ser aprobados por mayoría de los miembros presentes de la Cámara de Senadores.

El convenio establecerá las causas de la disolución del gobierno de coalición.

XVIII. a XX....

Artículo 90....

La función de Consejero Jurídico del Gobierno estará a cargo de la dependencia del Ejecutivo Federal que, para tal efecto, establezca la ley.

El Ejecutivo Federal representará a la Federación en los asuntos en que ésta sea parte, por conducto de la dependencia que tenga a su cargo la función de Consejero Jurídico del Gobierno o de las Secretarías de Estado, en los términos que establezca la ley.

\section{Artículo 93. ...}

Cualquiera de las Cámaras podrá convocar a los Secretarios de Estado, a los directores y administradores de las entidades paraestatales, así como a los titulares de los órganos autónomos, para que informen bajo protesta de decir verdad, cuando se discuta una ley o se estudie un negocio concerniente a sus respectivos ramos o actividades o para que respondan a interpelaciones o preguntas. 
...

I. a V ....

VI. No haber sido Secretario de Estado, Fiscal General de la República, senador, Diputado Federal ni Gobernador de algún Estado o Jefe de Gobierno del Distrito Federal, durante el año previo al día de su nombramiento.

...

Artículo 99 ....

$\cdots$

...

I. a VI. ...

VII. Los conflictos o diferencias laborales entre el Instituto Nacional Electoral $y$ sus servidores;

VIII. La determinación e imposición de sanciones por parte del Instituto Nacional Electoral a partidos o agrupaciones políticas o personas físicas o morales, nacionales o extranjeras, que infrinjan las disposiciones de esta Constitución $y$ las leyes;

IX. Los asuntos que el Instituto Nacional Electoral someta a su conocimiento por violaciones a lo previsto en la Base 111 del artículo 41 $y$ párrafo octavo del artículo 134 de esta Constitución; a las normas sobre propaganda política y electoral, así como por la realización de actos anticipados de precampaña o de campaña, e imponer las sanciones que correspondan, $y$

$\mathbf{X}$. Las demás que señale la ley.

...

Artículo 102.

A. El Ministerio Público se organizará en una Fiscalía General de la República como órgano público autónomo, dotado de personalidad jurídica y de patrimonio propios.

Para ser Fiscal General de la República se requiere: ser ciudadano mexicano por nacimiento; tener cuando menos treinta y cinco años cumplidos el día de la designación; contar, con antigüedad mínima 
de diez años, con título profesional de licenciado en derecho; gozar de buena reputación, y no haber sido condenado por delito doloso.

El Fiscal General durará en su encargo nueve años, y será designado y removido conforme a lo siguiente:

I. A partir de la ausencia definitiva del Fiscal General, el Senado de la República contará con veinte días para integrar una lista de al menos diez candidatos al cargo, aprobada por las dos terceras partes de los miembros presentes, la cual enviará al Ejecutivo Federal.

Si el Ejecutivo no recibe la lista en el plazo antes señalado, enviará libremente al Senado una terna y designará provisionalmente al Fiscal General, quien ejercerá sus funciones hasta en tanto se realice la designación definitiva conforme a lo establecido en este artículo. En este caso, el Fiscal General designado podrá formar parte de la terna.

II. Recibida la lista a que se refiere la fracción anterior, dentro de los diez días siguientes el Ejecutivo formulará una terna y la enviará a la consideración del Senado.

III. El Senado, con base en la terna y previa comparecencia de las personas propuestas, designará al Fiscal General con el voto de las dos terceras partes de los miembros presentes dentro del plazo de diez días.

En caso de que el Ejecutivo no envíe la terna a que se refiere la fracción anterior, el Senado tendrá diez días para designar al Fiscal General de entre los candidatos de la lista que señala la fracción I.

Si el Senado no hace la designación en los plazos que establecen los párrafos anteriores, el Ejecutivo designará al Fiscal General de entre los candidatos que integren la lista o, en su caso, la terna respectiva.

IV. El Fiscal General podrá ser removido por el Ejecutivo Federal por las causas graves que establezca la ley. La remoción podrá ser objetada por el voto de la mayoría de los miembros presentes de la Cámara de Senadores dentro de un plazo de diez días hábiles, en cuyo caso el Fiscal General será restituido en el ejercicio de sus funciones. Si el Senado no se pronuncia al respecto, se entenderá que no existe objeción.

V. En los recesos del Senado, la Comisión Permanente lo convocará de inmediato a sesiones extraordinarias para la designación o formulación de objeción a la remoción del Fiscal General.

VI. Las ausencias del Fiscal General serán suplidas en los términos que determine la ley. 
Corresponde al Ministerio Público la persecución, ante los tribunales, de todos los delitos del orden federal; y, por lo mismo, solicitará las medidas cautelares contra los imputados; buscará y presentará las pruebas que acrediten la participación de éstos en hechos que la leyes señalen como delito; procurará que los juicios federales en materia penal se sigan con toda regularidad para que la impartición de justicia sea pronta y expedita; pedirá la aplicación de las penas, e intervendrá en todos los asuntos que la ley determine.

La Fiscalía General contará, al menos, con las fiscalías especializadas en materia de delitos electorales y de combate a la corrupción, cuyos titulares serán nombrados y removidos por el Fiscal General de la República. El nombramiento y remoción de los fiscales especializados antes referidos podrán ser objetados por el Senado de la República por el voto de las dos terceras partes de los miembros presentes, en el plazo que fije la ley; si el Senado no se pronunciare en este plazo, se entenderá que no tiene objeción.

La ley establecerá las bases para la formación y actualización de los servidores públicos de la Fiscalía, así como para el desarrollo de la carrera profesional de los mismos, la cual se regirá por los principios de legalidad, objetividad, eficiencia, profesionalismo, honradez y respeto a los derechos humanos.

El Fiscal General presentará anualmente a los Poderes Legislativo y Ejecutivo de la Unión un informe de actividades. Comparecerá ante cualquiera de las Cámaras cuando se le cite a rendir cuentas o a informar sobre su gestión.

El Fiscal General de la República y sus agentes, serán responsables de toda falta, omisión o violación a la ley en que incurran con motivo de sus funciones.

B. ...

Artículo 105....

I. ...

II. ...

a) y b) ...

c) El Ejecutivo Federal, por conducto del Consejero Jurídico del Gobierno, en contra de normas generales de carácter federal y de las entidades federativas;

d) y e)... 
f) Los partidos políticos con registro ante el Instituto Nacional Electoral, por conducto de sus dirigencias nacionales, en contra de leyes electorales federales o locales; y los partidos políticos con registro estatal, a través de sus dirigencias, exclusivamente en contra de leyes electorales expedidas por el órgano legislativo del Estado que les otorgó el registro;

g) ...

h) El Fiscal General de la República respecto de leyes federales y de las entidades federativas, en materia penal y procesal penal, así como las relacionadas con el ámbito de sus funciones;

III. De oficio o a petición fundada del correspondiente Tribunal Unitario de Circuito o del Ejecutivo Federal, por conducto del Consejero Jurídico del Gobierno, así como del Fiscal General de la República en los asuntos en que intervenga el Ministerio Público, podrá conocer de los recursos de apelación en contra de sentencias de Jueces de Distrito dictadas en aquellos procesos en que la Federación sea parte y que por su interés y trascendencia así lo ameriten.

Artículo 107 ....

I. a IV....

V....

a) a d) ...

La Suprema Corte de Justicia, de oficio o a petición fundada del correspondiente Tribunal Colegiado de Circuito, del Fiscal General de la República, en los asuntos en que el Ministerio Público de la Federación sea parte, o del Ejecutivo Federal, por conducto del Consejero Jurídico del Gobierno, podrá conocer de los amparos directos que por su interés y trascendencia así lo ameriten.

VI. y VII. ...

VIII. ...

a) у b) ...

La Suprema Corte de Justicia, de oficio o a petición fundada del correspondiente Tribunal Colegiado de Circuito, del Fiscal General de la República, en los asuntos en que el Ministerio Público de la Fede- 
ración sea parte, o del Ejecutivo Federal, por conducto del Consejero Jurídico del Gobierno, podrá conocer de los amparos en revisión, que por su interés y trascendencia así lo ameriten.

IX. a XII ....

XIII. Cuando los Tribunales Colegiados de un mismo Circuito sustenten tesis contradictorias en los juicios de amparo de su competencia, el Fiscal General de la República, en asuntos en materia penal y procesal penal, así como los relacionados con el ámbito de sus funciones, los mencionados tribunales y sus integrantes, los Jueces de Distrito, las partes en los asuntos que los motivaron o el Ejecutivo Federal, por conducto del Consejero Jurídico del Gobierno, podrán denunciar la contradicción ante el Pleno del Circuito correspondiente, a fin de que decida la tesis que debe prevalecer como jurisprudencia.

Cuando las Salas de la Suprema Corte de Justicia de la Nación sustenten tesis contradictorias en los juicios de amparo cuyo conocimiento les competa, los ministros, los Tribunales Colegiados de Circuito y sus integrantes, los Jueces de Distrito, el Fiscal General de la República, en asuntos en materia penal y procesal penal, así como los relacionados con el ámbito de sus funciones, el Ejecutivo Federal, por conducto del Consejero Jurídico del Gobierno, o las partes en los asuntos que las motivaron, podrán denunciar la contradicción ante el Pleno de la Suprema Corte, conforme a la ley reglamentaria, para que éste resuelva la contradicción.

XIV....

XV. El Fiscal General de la República o el Agente del Ministerio Público de la Federación que al efecto designe, será parte en todos los juicios de amparo en los que el acto reclamado provenga de procedimientos del orden penal y aquéllos que determine la ley;

XVI. a XVIII. ...

Artículo 110. Podrán ser sujetos de juicio político los senadores y diputados al Congreso de la Unión, los ministros de la Suprema Corte de Justicia de la Nación, los Consejeros de la Judicatura Federal, los Secretarios de Despacho, los diputados a la Asamblea del Distrito Federal, el Jefe de Gobierno del Distrito Federal, el Fiscal General de la República, el Procurador General de Justicia del Distrito Federal, los magistrados de Circuito y jueces de Distrito, los magistrados y jueces del Fuero Común del Distrito Federal, los Consejeros de la Judicatura 
del Distrito Federal, el consejero Presidente, los consejeros electorales, y el secretario ejecutivo del Instituto Nacional Electoral, los magistrados del Tribunal Electoral, los integrantes de los órganos constitucionales autónomos, los directores generales y sus equivalentes de los organismos descentralizados, empresas de participación estatal mayoritaria, sociedades y asociaciones asimiladas a éstas y fideicomisos públicos.

Artículo 111. Para proceder penalmente contra los diputados y senadores al Congreso de la Unión, los ministros de la Suprema Corte de Justicia de la Nación, los magistrados de la Sala Superior del Tribunal Electoral, los consejeros de la Judicatura Federal, los Secretarios de Despacho, los diputados a la Asamblea del Distrito Federal, el Jefe de Gobierno del Distrito Federal, el Fiscal General de la República y el Procurador General de Justicia del Distrito Federal, así como el consejero Presidente y los consejeros electorales del Consejo General del Instituto Nacional Electoral, por la comisión de delitos durante el tiempo de su encargo, la Cámara de Diputados declarará por mayoría absoluta de sus miembros presentes en sesión, si ha o no lugar a proceder contra el inculpado.

Artículo 115. Los Estados adoptarán, para su régimen interior, la forma de gobierno republicano, representativo, democrático, laico y popular, teniendo como base de su división territorial y de su organización política y administrativa, el municipio libre, conforme a las bases siguientes:

I. ...

Las Constituciones de los Estados deberán establecer la elección consecutiva para el mismo cargo de presidentes municipales, regidores y síndicos, por un período adicional, siempre y cuando el periodo del mandato de los ayuntamientos no sea superior a tres años. 
La postulación sólo podrá ser realizada por el mismo partido o por cualquiera de los partidos integrantes de la coalición que lo hubieren postulado, salvo que hayan renunciado o perdido su militancia antes de la mitad de su mandato.

II. a X ....

Artículo $116 \ldots$

I. ...

II. ...

Las Constituciones estatales deberán establecer la elección consecutiva de los diputados a las legislaturas de los Estados, hasta por cuatro periodos consecutivos. La postulación sólo podrá ser realizada por el mismo partido o por cualquiera de los partidos integrantes de la coalición que los hubieren postulado, salvo que hayan renunciado o perdido su militancia antes de la mitad de su mandato.

Las legislaturas de los Estados se integrarán con diputados electos, según los principios de mayoría relativa y de representación proporcional, en los términos que señalen sus leyes. En ningún caso, un partido político podrá contar con un número de diputados por ambos principios que representen un porcentaje del total de la legislatura que exceda en ocho puntos su porcentaje de votación emitida. Esta base no se aplicará al partido político que por sus triunfos en distritos uninominales obtenga un porcentaje de curules del total de la legislatura, superior a la suma del porcentaje de su votación emitida más el ocho por ciento.

Asimismo, en la integración de la legislatura, el porcentaje de representación de un partido político no podrá ser menor al porcentaje de votación que hubiere recibido menos ocho puntos porcentuales.

III. ... 
IV. De conformidad con las bases establecidas en esta Constitución y las leyes generales en la materia, las Constituciones y leyes de los Estados en materia electoral, garantizarán que:

a) Las elecciones de los gobernadores, de los miembros de las legislaturas locales y de los integrantes de los ayuntamientos se realicen mediante sufragio universal, libre, secreto y directo; y que la jornada comicial tenga lugar el primer domingo de junio del año que corresponda. Los Estados cuyas jornadas electorales se celebren en el año de los comicios federales y no coincidan en la misma fecha de la jornada federal, no estarán obligados por esta última disposición;

b) En el ejercicio de la función electoral, a cargo de las autoridades electorales, sean principios rectores los de certeza, imparcialidad, independencia, legalidad, máxima publicidad y objetividad;

c) Las autoridades que tengan a su cargo la organización de las elecciones y las jurisdiccionales que resuelvan las controversias en la materia, gocen de autonomía en su funcionamiento, e independencia en sus decisiones, conforme a lo siguiente y lo que determinen las leyes:

$\mathbf{1}^{\circ}$. Los organismos públicos locales electorales contarán con un órgano de dirección superior integrado por un consejero Presidente y seis consejeros electorales, con derecho a voz y voto; el Secretario Ejecutivo y los representantes de los partidos políticos concurrirán a las sesiones sólo con derecho a voz; cada partido político contará con un representante en dicho órgano.

$\mathbf{2}^{\circ}$. El consejero Presidente y los consejeros electorales serán designados por el Consejo General del Instituto Nacional Electoral, en los términos previstos por la ley. Los consejeros electorales estatales deberán ser originarios de la entidad federativa correspondiente o contar con una residencia efectiva de por lo menos cinco años anteriores a su designación, y cumplir con los requisitos y el perfil que acredite su idoneidad para el cargo que establezca la ley. En caso de que ocurra una vacante de consejero electoral estatal, el Consejo General del Instituto Nacional Electoral hará la designación correspondiente en términos de este artículo y la ley. Sí la vacante se verifica durante los primeros cuatro años de su encargo, se elegirá un sustituto para concluir el período. Si la falta ocurriese dentro de los últimos tres años, se elegirá a un consejero para un nuevo periodo.

$3^{\circ}$. Los consejeros electorales estatales tendrán un período de desempeño de siete años y no podrán ser reelectos; percibirán una remuneración acorde con sus funciones y podrán ser removidos por el 
Consejo General del Instituto Nacional Electoral, por las causas graves que establezca la ley.

$4^{\circ}$. Los consejeros electorales estatales y demás servidores públicos que establezca la ley, no podrán tener otro empleo, cargo o comisión, con excepción de los no remunerados en actividades docentes, científicas, culturales, de investigación o de beneficencia. Tampoco podrán asumir un cargo público en los órganos emanados de las elecciones en cuya organización y desarrollo hubieren participado, ni ser postulados para un cargo de elección popular o asumir un cargo de dirigencia partidista, durante los dos años posteriores al término de su encargo.

$5^{\circ}$. Las autoridades electorales jurisdiccionales se integrarán por un número impar de magistrados, quienes serán electos por las dos terceras partes de los miembros presentes de la Cámara de Senadores, previa convocatoria pública, en los términos que determine la ley.

$\mathbf{6}^{\circ}$. Los organismos públicos locales electorales contarán con servidores públicos investidos de fe pública para actos de naturaleza electoral, cuyas atribuciones y funcionamiento serán reguladas por la ley.

$7^{\circ}$. Las impugnaciones en contra de los actos que, conforme a la base V del artículo 41 de esta Constitución, realice el Instituto Nacional Electoral con motivo de los procesos electorales locales, serán resueltas por el Tribunal Electoral del Poder Judicial de la Federación, conforme lo determine la ley.

d) Las autoridades electorales competentes de carácter administrativo puedan convenir con el Instituto Nacional Electoral se haga cargo de la organización de los procesos electorales locales;

e) ...

f) $\ldots$

El partido político local que no obtenga, al menos, el tres por ciento del total de la votación válida emitida en cualquiera de las elecciones que se celebren para la renovación del Poder Ejecutivo o Legislativo locales, le será cancelado el registro. Esta disposición no será aplicable para los partidos políticos nacionales que participen en las elecciones locales.

g) ...

h) Se fijen los criterios para establecer los límites a las erogaciones de los partidos políticos en sus precampañas y campañas electorales, así como los montos máximos que tengan las aportaciones de sus militantes y simpatizantes;

i) ... 
j) Se fijen las reglas para las precampañas y las campañas electorales de los partidos políticos, así como las sanciones para quienes las infrinjan. En todo caso, la duración de las campañas será de sesenta a noventa días para la elección de gobernador y de treinta a sesenta días cuando sólo se elijan diputados locales o ayuntamientos; las precampañas no podrán durar más de las dos terceras partes de las respectivas campañas electorales;

k) Se regule el régimen aplicable a la postulación, registro, derechos y obligaciones de los candidatos independientes, garantizando su derecho al financiamiento público y al acceso a la radio y la televisión en los términos establecidos en esta Constitución y en las leyes correspondientes;

1) y $\mathbf{m})$...

n) Se verifique, al menos, una elección local en la misma fecha en que tenga lugar alguna de las elecciones federales;

V. a VII....

VIII. Las Constituciones de los Estados garantizarán que las funciones de procuración de justicia se realicen con base en los principios de autonomía, eficiencia, imparcialidad, legalidad, objetividad, profesionalismo, responsabilidad y respeto a los derechos humanos.

\section{Artículo 119. ...}

Las entidades federativas están obligadas a entregar sin demora a los imputados o sentenciados, así como a practicar el aseguramiento y entrega de objetos, instrumentos o productos del delito, atendiendo a la autoridad de cualquier otra que los requiera. Estas diligencias se practicarán, con intervención de los respectivos órganos de procuración de justicia, en los términos de los convenios de colaboración que, al efecto, celebren las entidades federativas. Para los mismos fines, las autoridades locales podrán celebrar convenios de colaboración con la Fiscalía General de la República.
A. ...
B. ...
C....

Artículo 122. ...

BASE PRIMERA. ...

I. y II. ... 
III. En la integración de la Asamblea Legislativa del Distrito Federal invariablemente se observarán los criterios que establece el artículo 116, fracción 11, párrafo tercero, de esta Constitución;

IV. y V. ...

\section{BASE SEGUNDA a BASE QUINTA ... \\ D. a H....}

\section{TRANSITORIOS}

PRIMERO.- El presente Decreto entrará en vigor al día siguiente de su publicación en el Diario Oficial de la Federación, sin perjuicio de lo dispuesto en los transitorios siguientes.

SEGUNDO.- EI Congreso de la Unión deberá expedir las normas previstas en el inciso a) de la fracción XXI, y en la fracción XXIX-U del artículo 73 de esta Constitución, a más tardar el 30 de abril de 2014. Dichas normas establecerán, al menos, lo siguiente:

I. La ley general que regule los partidos políticos nacionales y locales:

a) Las normas, plazos y requisitos para su registro legal y su intervención en los procesos electorales federales y locales;

b) Los derechos y obligaciones de sus militantes y la garantía de acceso a los órganos imparciales de justicia intrapartidaria;

c) Los lineamientos básicos para la integración de sus órganos directivos; la postulación de sus candidatos y, en general, la conducción de sus actividades de forma democrática; así como la transparencia en el uso de los recursos;

d) Los contenidos mínimos de sus documentos básicos;

e) Los procedimientos y las sanciones aplicables al incumplimiento de sus obligaciones;

f) El sistema de participación electoral de los partidos políticos a través de la figura de coaliciones, conforme a lo siguiente:

1. Se establecerá un sistema uniforme de coaliciones para los procesos electorales federales y locales;

2. Se podrá solicitar su registro hasta la fecha en que inicie la etapa de precampañas;

3. La ley diferenciará entre coaliciones totales, parciales y flexibles. Por coalición total se entenderá la que establezcan los partidos políticos para postular a la totalidad de los candidatos en un mismo proceso electoral federal o local, bajo una misma plataforma electoral. Por 
coalición parcial se entenderá la que establezcan los partidos políticos para postular al menos el cincuenta por ciento de las candidaturas en un mismo proceso electoral federal o local, bajo una misma plataforma. Por coalición flexible se entenderá la que establezcan los partidos políticos para postular al menos el veinticinco por ciento de las candidaturas en un mismo proceso electoral federal o local, bajo una misma plataforma electoral; 4. Las reglas conforme a las cuales aparecerán sus emblemas en las boletas electorales y las modalidades del escrutinio y cómputo de los votos; 5 . En el primer proceso electoral en el que participe un partido político, no podrá coaligarse, y

g) Un sistema de fiscalización sobre el origen y destino de los recursos con los que cuenten los partidos políticos, las coaliciones y los candidatos, que deberá contener:

1. Las facultades y procedimientos para que la fiscalización de los ingresos y egresos de los partidos políticos, las coaliciones y los candidatos se realice de forma expedita y oportuna durante la campaña electoral;

2. Los lineamientos homogéneos de contabilidad, la cual deberá ser pública y de acceso por medios electrónicos;

3. Los mecanismos por los cuales los partidos políticos, las coaliciones y las candidaturas independientes deberán notificar al órgano de fiscalización del Instituto Nacional Electoral, la información sobre los contratos que celebren durante las campañas o los procesos electorales, incluyendo la de carácter financiero y la relativa al gasto y condiciones de ejecución de los instrumentos celebrados. Tales notificaciones deberán realizarse previamente a la entrega de los bienes o la prestación de los servicios de que se trate;

4. Las facultades del Instituto Nacional Electoral para comprobar el contenido de los avisos previos de contratación a los que se refiere el numeral anterior;

5. Los lineamientos para asegurar la máxima publicidad de los registros y movimientos contables, avisos previos de contratación y requerimientos de validación de contrataciones emitidos por la autoridad electoral;

6. La facultad de los partidos políticos de optar por realizar todos los pagos relativos a sus actividades y campañas electorales, por conducto del Instituto Nacional Electoral, en los términos que el mismo Instituto establezca mediante disposiciones de carácter general; 
7. La facultad de los partidos políticos de optar por realizar todos los pagos relativos a la contratación de publicidad exterior, por conducto del Instituto Nacional Electoral, y

8. Las sanciones que deban imponerse por el incumplimiento de sus obligaciones ..

II. La ley general que regule los procedimientos electorales:

a) La celebración de elecciones federales y locales el primer domingo de junio del año que corresponda, en los términos de esta Constitución, a partir del 2015, salvo aquellas que se verifiquen en 2018, las cuales se llevarán a cabo el primer domingo de julio;

b) Los mecanismos de coordinación entre los órganos del Ejecutivo Federal en materia de inteligencia financiera y el Instituto Nacional Electoral, que permitan reportar a éste las disposiciones en efectivo que realice cualquier órgano o dependencia de la Federación, de las entidades federativas y de los municipios durante cualquier proceso electoral, cuando tales operaciones se consideren relevantes o inusuales de conformidad con los ordenamientos aplicables;

c) Las reglas aplicables para transparentar el financiamiento, la metodología y los resultados de las encuestas que se difundan, relativas a las preferencias electorales, así como las fechas límite para llevar a cabo su difusión;

d) Los términos en que habrán de realizarse debates de carácter obligatorio entre candidatos, organizados por las autoridades electorales; y las reglas aplicables al ejercicio de la libertad de los medios de comunicación para organizar y difundir debates entre candidatos a cualquier cargo de elección popular. La negativa a participar de cualquiera de los candidatos en ningún caso será motivo para la cancelación o prohibición del debate respectivo. La realización o difusión de debates en radio y televisión, salvo prueba en contrario, no se considerará como contratación ilegal de tiempos o como propaganda encubierta;

e) Las modalidades y plazos de entrega de los materiales de propaganda electoral para efectos de su difusión en los tiempos de radio y televisión;

f) Las sanciones aplicables a la promoción de denuncias frívolas. Para tales efectos, se entenderá como denuncia frívola aquella que se promueva respecto a hechos que no se encuentren soportados en ningún medio de prueba o que no puedan actualizar el supuesto jurídico específico en que se sustente la queja o denuncia; 
Esta revista forma parte del acervo de la Biblioteca Jurídica Virtual del Instituto de Investigaciones Jurídicas de la UNAM

g) La regulación de la propaganda electoral, debiendo establecer que los artículos promociona les utilitarios sólo podrán ser elaborados con material textil;

h) Las reglas para garantizar la paridad entre géneros en candidaturas a legisladores federales y locales, e

i) Las reglas, plazos, instancias y etapas procesales para sancionar violaciones en los procedimientos electorales.

III. La ley general en materia de delitos electorales establecerá los tipos penales, sus sanciones, la distribución de competencias y las formas de coordinación entre la Federación y las entidades federativas.

TERCERO.- El Congreso de la Unión deberá expedir, durante el segundo periodo de sesiones ordinarias del segundo año de ejercicio de la LXII Legislatura, la ley que reglamente el párrafo octavo del artículo 134 de esta Constitución, la que establecerá las normas a que deberán sujetarse los poderes públicos, los órganos autónomos, las dependencias y entidades de la administración pública y de cualquier otro ente de los tres órdenes de gobierno, y que garantizará que el gasto en comunicación social cumpla con los criterios de eficiencia, eficacia, economía, transparencia y honradez, así como que respete los topes presupuestales, límites y condiciones de ejercicio que establezcan los presupuestos de egresos respectivos.

CUARTO.- Las adiciones, reformas y derogaciones que se hacen a los artículos 35; 41; 54; 55; 99; 105 fracción 11 inciso f); 110 y 111 por lo que hace a la denominación del Instituto Nacional Electoral, y 116 fracción IV, de esta Constitución, entrarán en vigor en la misma fecha en que lo hagan las normas a que se refiere el transitorio Segundo anterior, sin perjuicio de lo previsto en el transitorio Quinto siguiente.

La adición del cuarto párrafo a la base 1 del artículo 41 de esta Constitución, relativa al porcentaje de votación necesaria para que los partidos políticos conserven su registro, entrará en vigor al día siguiente de la publicación del presente Decreto.

Las reformas a que se refiere el primer párrafo del presente transitorio, respecto de entidades federativas que tengan procesos electorales en 2014, entrarán en vigor una vez que hayan concluido dichos procesos.

QUINTO.- El Instituto Nacional Electoral deberá integrarse dentro de los ciento veinte días naturales siguientes a la entrada en vigor del presente Decreto y comenzará a ejercer sus atribuciones a partir de que entren en vigor las normas previstas en el transitorio Segundo 
anterior. En caso de que a la fecha de integración del Instituto Nacional Electoral no hubieren entrado en vigor las normas previstas en el transitorio Segundo anterior, dicho Instituto ejercerá las atribuciones que las leyes vigentes otorgan al Instituto Federal Electoral.

Con el objeto de asegurar el escalonamiento en el cargo de los integrantes del Consejo General del Instituto Nacional Electoral, el comité de evaluación a que se refiere el inciso a) del párrafo quinto del Apartado A de la Base V del artículo 41, que se reforma por virtud del presente Decreto, deberá remitir a la Cámara de Diputados para su trámite en procesos separados, conforme a lo previsto en el referido párrafo:

a) Tres listas para cubrir la elección de cada uno de los tres consejeros que durarán en su encargo tres años;

b) Cuatro listas para cubrir la elección de cada uno de los cuatro consejeros que durarán en su encargo seis años;

c) Tres listas para cubrir la elección de cada uno de los tres consejeros que durarán en su encargo nueve años, y

d) Una lista para cubrir la elección del Presidente que durará en su encargo nueve años.

Los consejeros del Instituto Federal Electoral que se encuentren en funciones al inicio del procedimiento de selección para la integración del Instituto Nacional Electoral, podrán participar en dicho proceso.

SEXTO.- Una vez integrado y a partir de que entren en vigor las normas previstas en el transitorio Segundo anterior, el Instituto Nacional Electoral deberá expedir los lineamientos para garantizar la incorporación de todos los servidores públicos del Instituto Federal Electoral y de los organismos locales en materia electoral, al Servicio Profesional Electoral Nacional, así como las demás normas para su integración total.

SÉPTIMO.- Los recursos humanos, presupuestales, financieros y materiales del Instituto Federal Electoral, pasarán a formar parte del Instituto Nacional Electoral una vez que quede integrado en términos del transitorio Quinto anterior; sin menoscabo de los derechos laborales.

OCTAVO.- Una vez integrado el Instituto Nacional Electoral y a partir de que entren en vigor las normas previstas en el transitorio Segundo anterior, las funciones correspondientes a la capacitación electoral, así como la ubicación de las casillas y la designación de fun- 
Esta revista forma parte del acervo de la Biblioteca Jurídica Virtual del Instituto de Investigaciones Jurídicas de la UNAM

cionarios de la mesa directiva, en los procesos electorales locales, se entenderán delegadas a los organismos públicos locales.

En este caso, el Instituto Nacional Electoral podrá reasumir dichas funciones, por mayoría del Consejo General.

La delegación y reasunción posteriores de estas atribuciones se someterá a lo dispuesto en la Base V, Apartado C del artículo 41 de esta Constitución.

NOVENO.- El Consejo General del Instituto Nacional Electoral designará a los nuevos consejeros de los organismos locales en materia electoral, en términos de lo dispuesto por el inciso e) de la fracción IV del artículo 116 de esta Constitución. Los actuales consejeros continuarán en su encargo hasta en tanto se realicen las designaciones a que se refiere el presente transitorio. El Consejo General llevará a cabo los procedimientos para que el nombramiento de los consejeros electorales se verifique con antelación al siguiente proceso electoral posterior a la entrada en vigor de este Decreto.

DÉCIMO.- Los Magistrados de los órganos jurisdiccionales locales en materia electoral, que se encuentren en funciones a la entrada en vigor de las normas previstas en el transitorio Segundo, continuarán en su encargo hasta en tanto se realicen los nuevos nombramientos, en los términos previstos por la fracción IV, inciso e), del artículo 116 de esta Constitución. El Senado de la República llevará a cabo los procedimientos para que el nombramiento de los magistrados electorales se verifique con antelación al inicio del siguiente proceso electoral local posterior a la entrada en vigor de este Decreto.

Los magistrados a que se refiere el párrafo anterior serán elegibles para un nuevo nombramiento.

DÉCIMO PRIMERO.- La reforma al artículo 59 de esta Constitución será aplicable a los diputados y senadores que sean electos a partir del proceso electoral de 2018 ..

DÉCIMO SEGUNDO.- Las adiciones, reformas y derogaciones que se hacen a los artículos 69 párrafo tercero; 74, fracciones III y VIII; 76, fracciones II y XI; 89, fracción II, párrafos segundo y tercero, y fracción XVII, entrarán en vigor el 1 de diciembre de 2018.

DÉCIMO TERCERO.- La reforma al artículo 116 de esta Constitución en materia de reelección de diputados locales, así como a diputados a la Asamblea Legislativa del Distrito Federal, no será aplicable a los legisladores que hayan protestado el cargo en la legislatura que se encuentre en funciones a la entrada en vigor del presente Decreto. 
DÉCIMO CUARTO.- La reforma al artículo 115 de esta Constitución en materia de reelección de presidentes municipales, regidores y síndicos no será aplicable a los integrantes que hayan protestado el cargo en el Ayuntamiento que se encuentre en funciones a la entrada en vigor del presente Decreto.

DÉCIMO QUINTO.- Las reformas a los artículos 65; 74 fracción IV, y 83 de esta Constitución entrarán en vigor el 1 o de diciembre de 2018, por lo que el período presidencial comprendido entre los años 2018 y 2024 iniciará el $1^{\circ}$ de diciembre de 2018 y concluirá el 30 de septiembre de 2024.

DÉCIMO SEXTO.- Las adiciones, reformas y derogaciones que se hacen a los artículos 28; 29, párrafo primero; 69, párrafo segundo; 76, fracciones 11 , por lo que se refiere a la supresión de la ratificación del Procurador General de la República por el Senado y XII; 78, fracción V; 82, fracción VI; 84; 89, fracción IX; 90; 93, párrafo segundo; 95; 102, Apartado A; 105, fracciones 11, incisos e) y h), y 111; 107; 110 y 111 por lo que se refiere al Fiscal General de la República; 116 fracción VIII, y 119, párrafo primero de esta Constitución, entrarán en vigor en la misma fecha en que lo hagan las normas secundarias que expida el Congreso de la Unión necesarias por virtud de las adiciones, reformas y derogaciones a que se refiere el presente transitorio, siempre que se haga por el propio Congreso la declaratoria expresa de entrada en vigor de la autonomía constitucional de la Fiscalía General de la República.

El Procurador General de la República que se encuentre en funciones al momento de expedirse la declaratoria a que se refiere el párrafo anterior, quedará designado por virtud de este Decreto Fiscal General de la República por el tiempo que establece el artículo 102, apartado A, de esta Constitución, sin perjuicio del procedimiento de remoción previsto en la fracción IV de dicho artículo.

DÉCIMO SÉPTIMO.- Una vez que entren en vigor las disposiciones de este Decreto referidas en el transitorio anterior, se procederá de la siguiente forma:

I.- Los asuntos en los que la Procuraduría General de la República ejerza la representación de la Federación, así como aquellos en que haya ejercitado acciones de inconstitucionalidad en casos distintos a los previstos en el inciso h) de la fracción II, del artículo 105 de esta Constitución que se adiciona por virtud de este Decreto, que se encuentren en trámite a la entrada en vigor de las disposiciones a que se 
Esta revista forma parte del acervo de la Biblioteca Jurídica Virtual del Instituto de Investigaciones Jurídicas de la UNAM

refiere el transitorio anterior, deberán remitirse dentro de los veinte días hábiles siguientes a la dependencia del Ejecutivo Federal que realiza la función de Consejero Jurídico del Gobierno.

Los procedimientos señalados en el párrafo que antecede se suspenderán por un plazo de sesenta días hábiles, contados a partir de la entrada en vigor de las disposiciones a que se refiere el transitorio anterior; en cada caso, la suspensión será decretada de oficio por los órganos jurisdiccionales ante los cuales se desahoguen dichos procedimientos, y

II.- Los recursos humanos, financieros y materiales que la Procuraduría General de la República destine para la atención y desahogo de los procedimientos a que se refiere la fracción anterior, serán transferidos a la dependencia que realice las funciones de Consejero Jurídico del Gobierno. Los titulares de ambos órganos realizarán las previsiones necesarias para que dichos recursos queden transferidos el mismo día en que entren en vigor las disposiciones señaladas en el transitorio anterior.

DÉCIMO OCTAVO.- A partir de la entrada en vigor del presente Decreto el Senado nombrará por dos terceras partes de sus miembros presentes al titular de la Fiscalía Especializada en Atención de Delitos Electorales de la Procuraduría General de la República. El Ejecutivo Federal podrá objetar dicho nombramiento, en cuyo caso se procederá a un nuevo nombramiento en los términos de este párrafo.

En el plazo de treinta días a partir de la entrada en vigor de este Decreto, el Procurador General de la República expedirá el acuerdo de creación de la fiscalía especializada en materia de delitos relacionados con hechos de corrupción, cuyo titular será nombrado por el Senado en los términos del párrafo anterior.

Los titulares de las fiscalías nombrados en términos del presente transitorio durarán en su encargo hasta el treinta de noviembre de dos mil dieciocho, sin perjuicio de que puedan ser removidos libremente por el Procurador General de la República o, en su caso, del Fiscal General de la República. La remoción podrá ser objetada por el voto de la mayoría de los miembros presentes de la Cámara de Senadores dentro de un plazo de diez días hábiles, en cuyo caso el titular de la Fiscalía de que se trate, será restituido en el ejercicio de sus funciones.

DÉCIMO NOVENO.- A partir de la entrada en vigor de las reformas a que se refiere el transitorio Décimo Sexto anterior, los recursos humanos, presupuestales, financieros y materiales de la Procuraduría 
General de la República pasarán al órgano autónomo que el propio Decreto establece.

VIGÉSIMO.- La reforma al artículo 26 de esta Constitución entrará en vigor al día siguiente de la publicación del presente Decreto.

El Consejo General del Consejo Nacional para la Evaluación de la Política de Desarrollo Social deberá integrarse dentro de los sesenta días naturales siguientes a la entrada en vigor del presente Decreto. Para dicho efecto, se deberán elegir dos consejeros por un periodo de dos años, dos por un periodo de tres años, dos por un periodo de cuatro años y un consejero presidente por un periodo de cuatro años. En caso de que en el plazo referido no quede integrado el órgano constitucional referido y hasta su integración, continuará en sus funciones el organismo descentralizado denominado Consejo Nacional para la Evaluación de la Política de Desarrollo Social.

Con excepción del Secretario de Desarrollo Social, los integrantes del Comité Directivo del organismo descentralizado referido en el párrafo anterior, que se encuentren en funciones a la entrada en vigor del presente Decreto, podrán ser considerados para integrar el nuevo órgano autónomo que se crea.

El Congreso de la Unión deberá expedir la ley que regirá al órgano autónomo denominado Consejo Nacional para la Evaluación de la Política de Desarrollo Social, dentro de los ciento veinte días naturales siguientes a la entrada en vigor del presente Decreto.

En tanto el Congreso de la Unión expide la Ley a que se refiere el párrafo anterior, el Consejo Nacional para la Evaluación de la Política de Desarrollo Social que se crea por virtud del presente Decreto, una vez instalado, ejercerá sus atribuciones y competencias conforme a lo dispuesto en el mismo y en el Decreto por el que se regula el Consejo Nacional de Evaluación de la Política de Desarrollo Social, publicado en el Diario Oficial de la Federación el 24 de agosto de 2005.

VIGÉSIMO PRIMERO.- Los Consejeros del Instituto Federal Electoral que a la entrada en vigor del presente Decreto se encuentren en funciones, continuarán en su encargo hasta que se integre el Instituto Nacional Electoral, en términos de lo previsto por el Quinto Transitorio del presente Decreto; por lo que los actos jurídicos emitidos válidamente por el Instituto Federal Electoral en los términos de la legislación vigente, surtirán todos sus efectos legales. 
Esta revista forma parte del acervo de la Biblioteca Jurídica Virtual del Instituto de Investigaciones Jurídicas de la UNAM www.juridicas.unam.mx

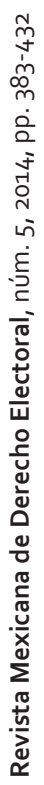
HONORABLE CÁMARA DE SENADORES.- México, D.F., a 13 de diciembre de 2013. 